\title{
Microstructure tailoring in nanostructured thermoelectric materials
}

\author{
Qinghui Jiang*, ${ }^{*}$, Junyou Yang*, Y, Yong Liu ${ }^{\dagger}$ and Hongcai He \\ *State Key Laboratory of Materials Processing and Die \& Mould Technology \\ and School of Materials Science and Engineering Huazhong University of Science and \\ Technology, Wuhan 430074, P. R. China \\ $\dagger^{\dagger}$ Beijing Institute of Aeronautical Materials, AVIC, Beijing 100095, P. R. China \\ ${ }^{*}$ State Key Laboratory of Electronic Thin Films and Integrated Devices \\ and School of Microelectronics and Solid-State Electronics, University of Electronic \\ Science and Technology of China, Chengdu 610054, P. R. China \\ \$qjiang@ hust.edu.cn \\ Tyyang@ @ust.edu.cn
}

Received 16 December 2015; Revised 23 January 2016; Accepted 4 February 2016; Published 31 March 2016

\begin{abstract}
Progresses in thermoelectric (TE) materials will contribute to solving the world's demands for energy and global climate protection. It also calls for higher ZT to achieve ideal commercial conversion efficiency. As an effective way, nanostructuring can reduce the thermal conductivity by the selective scattering of phonons or enhance Seebeck coefficient via modification of the density of the states, resulting in good ZT value. Meanwhile, TE properties of nanostructured materials should depend on the size and morphology of the microstructure features. This review emphasizes the developments in the TE bulk materials at the nanoscale in the past several years and summarizes the understanding in this active field.
\end{abstract}

Keywords: Review; thermoelectric; nanostructure; spark plasma sintering; microstructure tailoring.

\section{Introduction}

There is an ever-increasing demand for alternative energy technologies to reduce our reliance on fossil fuels. Thermoelectric (TE) materials can utilize waste heat energy and convert a temperature gradient into useful electrical energy, as well as produce refrigeration effect when an electric current passes through TE materials. They have received increasing attention not only because of promising potential applications in the energy generation, sensors, and solid state cooling, but also for their additional potential advantages that they could be: small, inexpensive, lightweight, quiet, long-life and pollution-free. So far, many commercial applications have been realized. For example, TE materials are successfully used in the electric water pump, climate control seat and TE Generator of BMW Series five cars. ${ }^{1}$ They are also the key in the radioisotope TE generators which provide power for the Cassini spacecraft. ${ }^{2}$ Meanwhile, recent several exciting works give the scientists more driving force to find their applications in other research area, such as dye-sensitized solar cells ${ }^{3}$ and lithium-ion batteries. ${ }^{4}$

The efficiency of actual TE devices is determined by the TE figure of merit, ZT. These applications call for TE materials with high ZT which require higher Seebeck coefficient, higher electrical conductivity and lower thermal conductivity. Up to now, there are many compounds which have excellent ZT value or low cost for potential industrial applications (which were discussed in detail in other excellent reviews ${ }^{5-8}$ ). Researchers have been exploring many methods to further improve properties of TE materials. Nanostructuring is regarded as an effective way, which can reduce the thermal conductivity by the selective scattering of phonons or enhance Seebeck coefficient via modification of the density of the states, resulting in good ZT value. In this paper, we focus on fabrication techniques of the TE bulk materials at multi-level nanoscales in the past several years and give some understanding in this active field.

\section{TE Effects and Size Dependent Properties}

When temperature gradient is applied to some materials, free carriers (either electrons or holes) will move from the hot side to the cold side, which will lead to the appearance of open circuit voltage. This phenomenon is called Seebeck effect. Meanwhile, if an electrical current is applied along the materials, there will be a temperature gradient between two sides of the samples, which is called Peltier effect. These TE effects were already known before about 200 years. As the initial application, this kind of materials were only used as

\footnotetext{
§, Corresponding authors.
}

This is an Open Access article published by World Scientific Publishing Company. It is distributed under the terms of the Creative Commons Attribution 4.0 (CC-BY) License. Further distribution of this work is permitted, provided the original work is properly cited. 
extremely reliable and long-lived powder sources in the irreplaceable area such as deep space missions because of its low TE conversion efficiency $\left(\eta_{\mathrm{te}}\right)$.

In the past 10 years, energy crisis and environmental protection evoke the new requirements for reliable, safe and green renewable energy. Meanwhile, extra abundant industrial waste heats need to be recycled, which make up 60-70\% of total energy consumption. TE materials are promising and competitive in these areas. Meanwhile, they can also be used as refrigeration modules due to their long-life and free chlorofluorocarbons (CFCs). For all these applications, higher $\eta_{\text {te }}$ demands some improvements in TE materials: (a) higher ZT values, (b) lower thermal conductivity and (c) good thermal shock resistance.

TE figure of merit

$$
\mathrm{ZT}=\frac{\text { PowerFactor }}{\kappa} T=\frac{S^{2} \sigma}{\kappa_{e}+\kappa_{l}+\kappa_{b}} T,
$$

where $S$ is Seebeck coefficient, $\sigma$ is electrical conductivity and $\kappa$ is thermal conductivity $\left(\kappa_{e}, \kappa_{l}\right.$ and $\kappa_{b}$ is electronic, lattice and bipolar thermal conductivity, respectively). ${ }^{9}$ Seebeck coefficient can be measured and calculated by dividing voltage gradient by temperature gradient. Thermal conductivity can be measured via laser flash method. The current challenge in this field is to increase ZT. High ZT requires high power factor (i.e., high Seebeck, high electrical conductivity) but low thermal conductivity. It looks simple. However, there are strong interconnections between these parameters, which make it very difficult to get higher ZT value. $\mathrm{ZT}$ value $\sim 1$ was a milestone as TE materials for near 40 years since 1960 s.

Theoretical predictions and the related experimentals show that low dimensional nanostructures, superlattices and quantum dots/well structures have shown higher ZT $(>3)$ because of quantum confinement. Therefore, there is still a great need for high-performance TE materials based on the bulk form. Meanwhile, the study of traditional bulk TE materials was revived by the utilization of nanotechnology. Nanostructuring can reduce the thermal conductivity by the selective scattering of phonons as a result of much higher density of grain boundaries, and enhance Seebeck coefficient via modification of the density of the states. The TE properties of nanostructured materials also depend on the size and morphology of the microstructure features, so microstructure engineering should become increasingly important in the development of TE nanomaterials. Herein, we focus on the synthesis and consolidation of nanostructured bulk TE materials in the past 10 years.

\section{Synthesis of Nanopowders}

Since the samples with nanograins or more grain boundaries have lower thermal conductivity and higher ZT value, nanopowders with homogenous size distribution should be prepared before the following consolidation process. There are three routes to fabricate single-phase bulk with nanograins: "bottom to top", "top to bottom", and in situ from deformation. For both the "bottom to top" approach and the "top to bottom" approach, the synthesized nanopowders should be sintered to bulk samples via hot pressing or spark plasma sintering (SPS) process.

\subsection{A bottom-top approach}

Several chemical methods are used to get nanopowders as a bottom-top approach. In these processes, several chemicals are first dissolved in the special solvent so that different elements can be mixed in the atomic level. After the controlling of the reaction environment or heat treatment condition, the nanopowders with tens of nanometers can be obtained. This preparation of nanopowders from the bottom/ atomic level is much homogenous and needs less energy, which was first used to synthesize quantum dots or functional nanopowders with (ferro)magnetic, ferroelectric or photocatalysis applications.

\subsubsection{Co-precipitation}

The co-precipitation method is the main processes to synthesize oxides nanopowders with highest yield. In the co-precipitation process, the salts with metal cations were dissolved in the water or other liquid and the hydroxide (such as $\mathrm{NaOH}, \mathrm{KOH}$ and $\mathrm{NH}_{3} \mathrm{H}_{2} \mathrm{O}$ ) was added to the solutions which led to the co-precipitation of metal cations in the appropriate $\mathrm{pH}$ value. Most TE oxide nanopowders can be obtained via this method, such as $\mathrm{CaMnO}_{3},{ }^{10,11}$ and $\mathrm{Bi}_{2} \mathrm{~A}_{2} \mathrm{CoO}_{6}{ }^{12}$

Some copper-contained selenide $\left(\mathrm{Cu}_{3} \mathrm{SbSe}_{4},{ }^{13} \mathrm{Cu}_{2} \mathrm{Se}^{14}\right)$, telluride $\left(\mathrm{Bi}_{2} \mathrm{Te}_{3},{ }^{15} \mathrm{PbTe}^{16}\right)$ and some sulfide $\left(\mathrm{PbZnS},{ }^{17}\right.$ $\mathrm{Cu}_{3} \mathrm{Sb}(\mathrm{SeS})^{18}$ ) can be also prepared via the co-precipitation method. Saleemi et al. ${ }^{19}$ prepared $\mathrm{Bi}_{2} \mathrm{Te}_{3}$ powders by reduced co-precipitation method and then bulk samples were consolidated using SPS, respectively. Compared to the conventional solid state synthesis, co-precipitation process, combined with SPS, can restrain the grain growth so that nanoceramics bulk can be obtained with improved TE properties. As shown in Fig. 1, the average grain size was about $90 \mathrm{~nm}$, and an improved ZT for bulk undoped $\mathrm{Bi}_{2} \mathrm{Te}_{3}$ is achieved with a peak value of 1.1 at $340 \mathrm{~K}$.

Li et al. used ethylenediamine ${ }^{13}$ as the solvent and is also a reducing agent and a ligand. Metal chlorides and Se powders were put into the glass beaker with the solvent. $\mathrm{CuCl}$ and $\mathrm{SbCl}_{3}$ were slowly dissolved in ethylenediamine to form the complexes at room temperature and $\mathrm{Cu}^{+}$and $\mathrm{Sb}^{3+}$ and $\mathrm{Sb}^{3+}$ were reduced to active atomic $\mathrm{Cu}, \mathrm{Sb}$. These active atoms combined with elemental selenium which was dissolved in ethylenediamine at $150^{\circ} \mathrm{C}$. As a result, flake-like $\mathrm{Cu}_{3} \mathrm{SbSe}_{4}$ nanopowders can be obtained (as shown in Fig. 2). However, the yield of this process is not so high and the aggregation of the nanopowders is inevitable. 

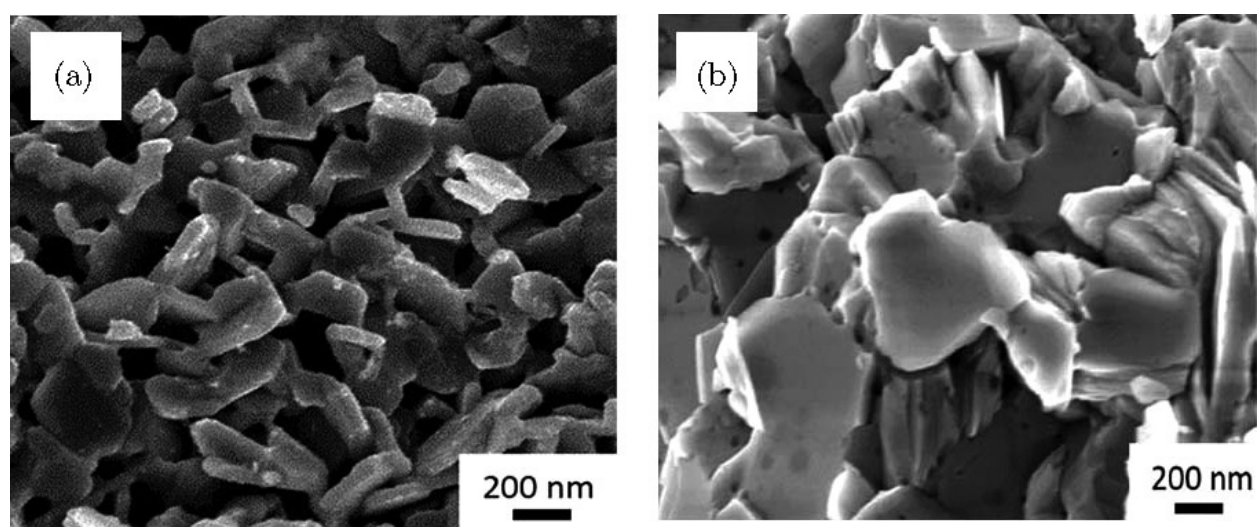

Fig. 1. (a) SEM pictures of nanopowders and (b) bulk sample $\mathrm{Bi}_{2} \mathrm{Te}_{3}$ sintered via SPS at $400^{\circ} \mathrm{C}$ samples (reproduced from Ref. 19 with permission from The Royal Society of Chemistry).

\subsubsection{Sol-gel/auto-combustion synthesis}

Compared with co-precipitation of oxide powders, sol-gel method (which is also called Pechini method, and autocombustion synthesis) is more competitive because the powders from this method have less hard aggregation and lower calcination temperature. ${ }^{20}$ Traditional sol-gel method was used to synthesize titanium oxide nanopowders (such as $\mathrm{SrTiO}_{3}$ ) with tetrabutyl titanate as the chelating agent. ${ }^{21}$

In the Pechini process, metal nitrates or acetates are blended in water or other solvent with the chelating agent such as citric acid, maleic acid, or ethylene glycol. The polycondensation of ethylene glycol and citric acid leads to the formation of citrate gel. Above $400^{\circ} \mathrm{C}$, oxidation and pyrolysis of the polymer matrix begin. If ammonia was used to adjust $\mathrm{pH}$ value, $\mathrm{NH}_{4} \mathrm{NO}_{3}$ will also decompose and release much heat, which leads to auto combustion of the gel (the inner temperature be above $900^{\circ} \mathrm{C}$ ) (so this process is called as auto-combustion synthesis). As a result, oxides nanopowders can be easily obtained in a short time. $\mathrm{Ca}_{3} \mathrm{Co}_{4} \mathrm{O}_{9},{ }^{22,23}$ and $\mathrm{LaCoO}_{3}{ }^{24}$ ceramic powders were
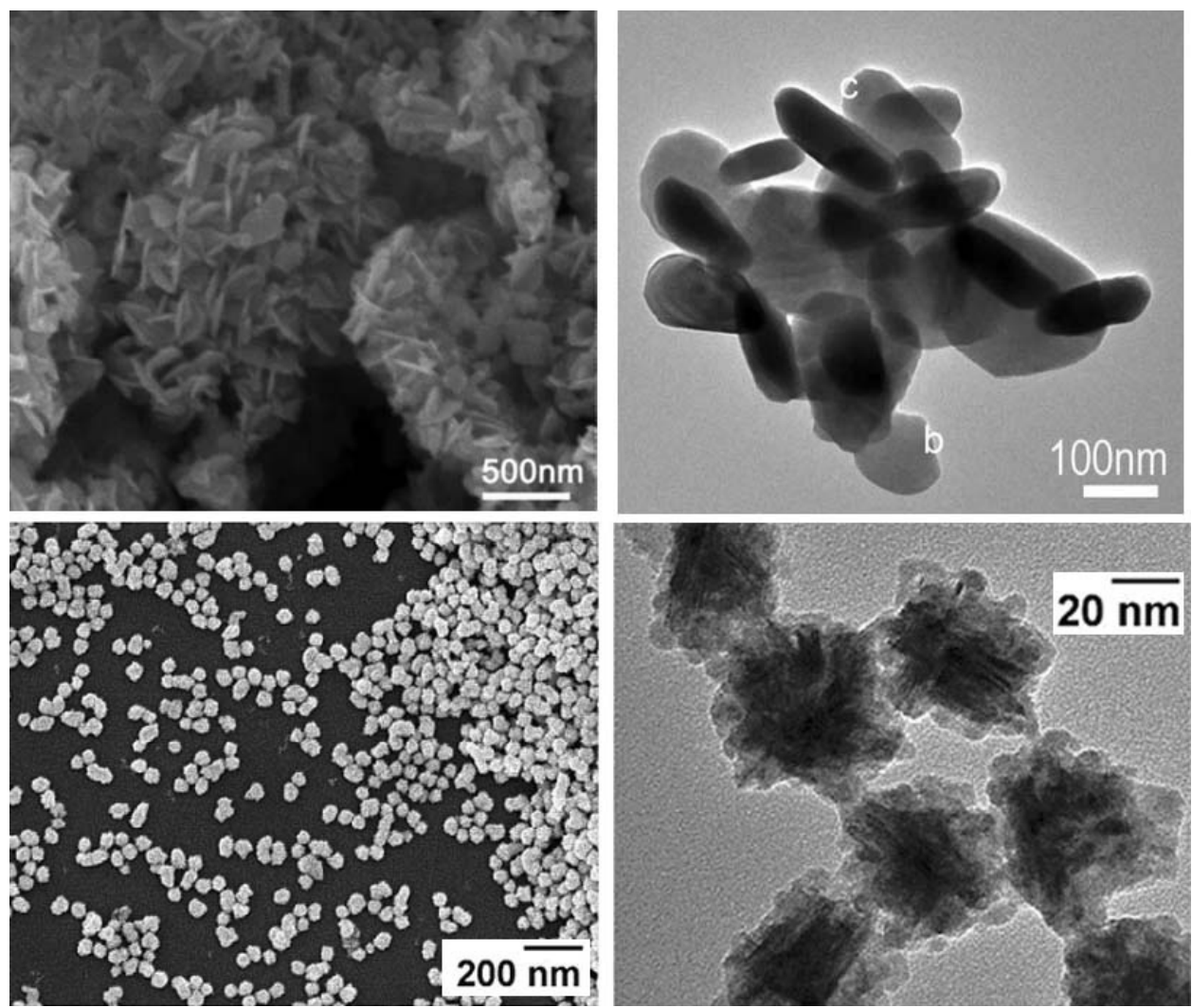

Fig. 2. SEM pictures of $\mathrm{Cu}_{3} \mathrm{SbSe}_{4}$ powders (reproduced from Ref. 13 with permission from The Royal Society of Chemistry) prepared via coprecipitation. 
successfully prepared via this method and ZT values were enhanced to a certain extent.

Meanwhile, there is similar phenomenon (which is called as "self-propagating high-temperature synthesis") in the synthesis of $\mathrm{Cu}_{2} \mathrm{Se}$ powders. ${ }^{25}$ Stoichiometric amounts of copper and selenium powders were mixed in the agate mortar and were sealed in a silica tube under near vacuum. Above the ignition point, the powders can self-ignite. The particle size of the matrix remains at about $1-3 \mu \mathrm{m}$ and there are many nano dots in the microclusters (as shown in Figs. 3(a) and 3(b)). Because dense samples cannot be got via this auto combustion, further consolidation via SPS process is needed (Figs. 3(c) and 3(d)). This process is effective for many TE compounds such as $\mathrm{Bi}_{2} \mathrm{Te}_{3}, \mathrm{Mg}_{2} \mathrm{Si}$, SnTe and $\mathrm{CoSb}_{3}$. ZT values of these samples fabricated via combining auto combustion with SPS are similar or better than those synthesized by other methods.

\subsubsection{Hydrothermal method}

Initially, hydrothermal method was used to grow single crystals like quartz, gems or other functional crystals. Several parameters have key roles on the growth of crystals: initial $\mathrm{pH}$ value of the solvent, the reaction temperature (or environment pressure) and soaking time. After the addition of proper surfactant agent, many nanoparticles (NPs) will appear when the crystallization rate and nucleation rate of amorphous phases sharply increase in hydrothermal conditions. One of the most widely known nanomaterials produced by the hydrothermal method is $\mathrm{Bi}_{2} \mathrm{Te}_{3}$-based compound. Many groups successfully prepared $\mathrm{Bi}_{2} \mathrm{Te}_{3}$-based compounds with different morphologies such as nanotubes, ${ }^{26}$ nanowires, ${ }^{27}$ self-assembled flowers ${ }^{28}$ or nanoplates ${ }^{29}$ via this method (as shown in Fig. 4). Unfortunately, ZT values of samples after the consolidation of SPS are only about or less than $0.7,{ }^{30,31}$ which is much lower than that of samples prepared via other methods. Just for these samples, dense nanostructures can result in greatly enhanced phonon scattering, and therefore the thermal conductivity is dramatically decreased to nearly minimum values. Other compounds such as PbTe, ${ }^{32} \mathrm{CoSb}_{3}{ }^{-33} \mathrm{Bi}_{2} \mathrm{~S}_{3},{ }^{34} \mathrm{Nb}$-doped $\mathrm{TiO}_{2}{ }^{35}$ and $\mathrm{SrTiO}_{3}{ }^{36}$ can also be synthesized via hydrothermal method. The advantage of this method is to synthesize the nanostructure with controlled morphologies with narrow grain size distribution, and the samples from these powders have ultra or much lower thermal conductivity. The disadvantages are: (1) to requirement of special vessels like autoclave or three neck flask; (2) low scale production from high pressure, high temperature and long reaction time; (3) toxicity from the reducing agents or oily solvent; (4) high cost with the usage of organic chemicals and (5) low ZT value from the high resistivity due to point or other crystal defects. So the challenge is to find a recipe with low cost, nontoxic and large yield.

\subsubsection{Microwave-assisted method}

The microwave-assisted method attracted much interest due to a high reaction rate and over a short reaction time. At high
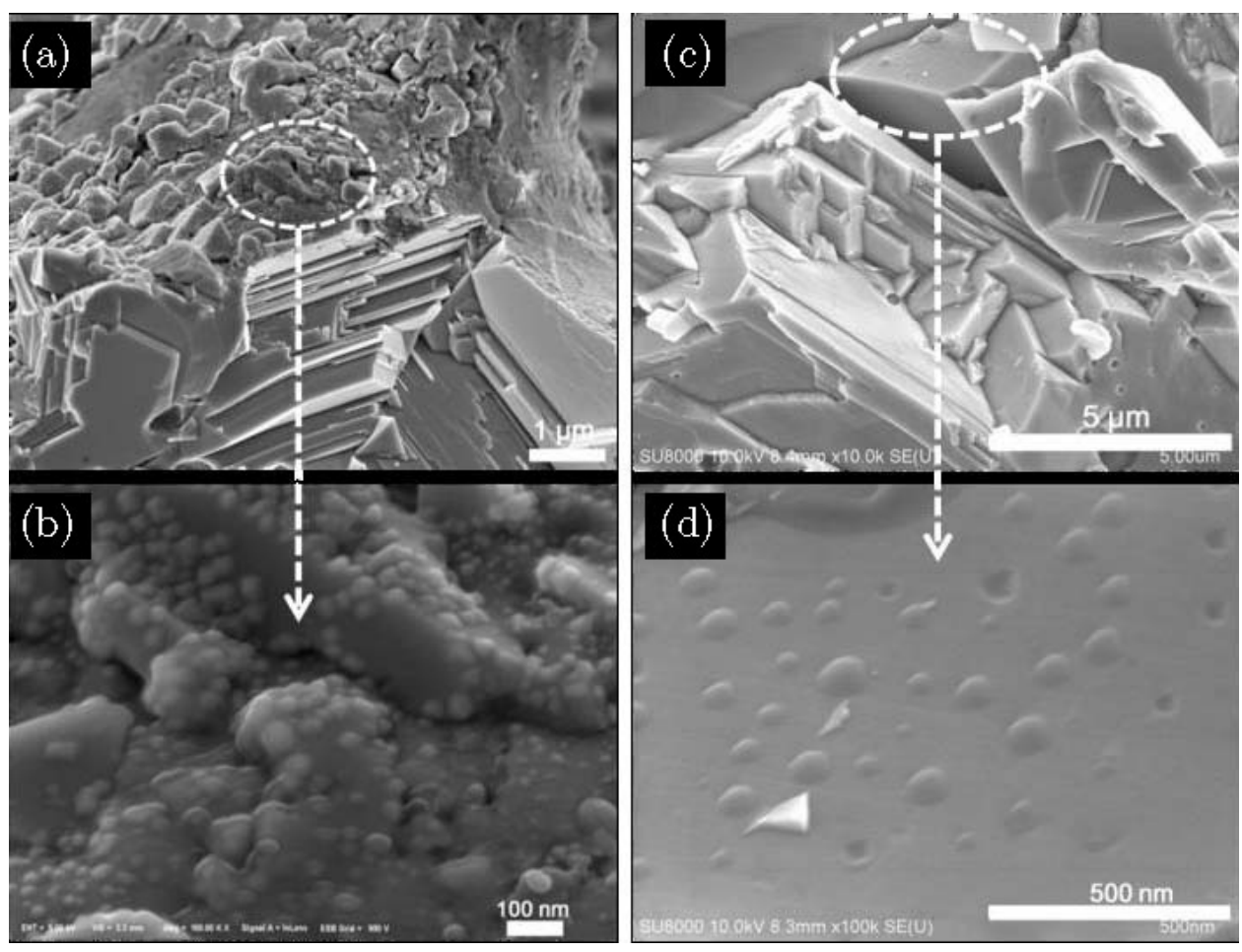

Fig. 3. (a), (b) SEM images of the SHS powders and (c), (d) SHS-SPS bulk. ${ }^{25}$ 

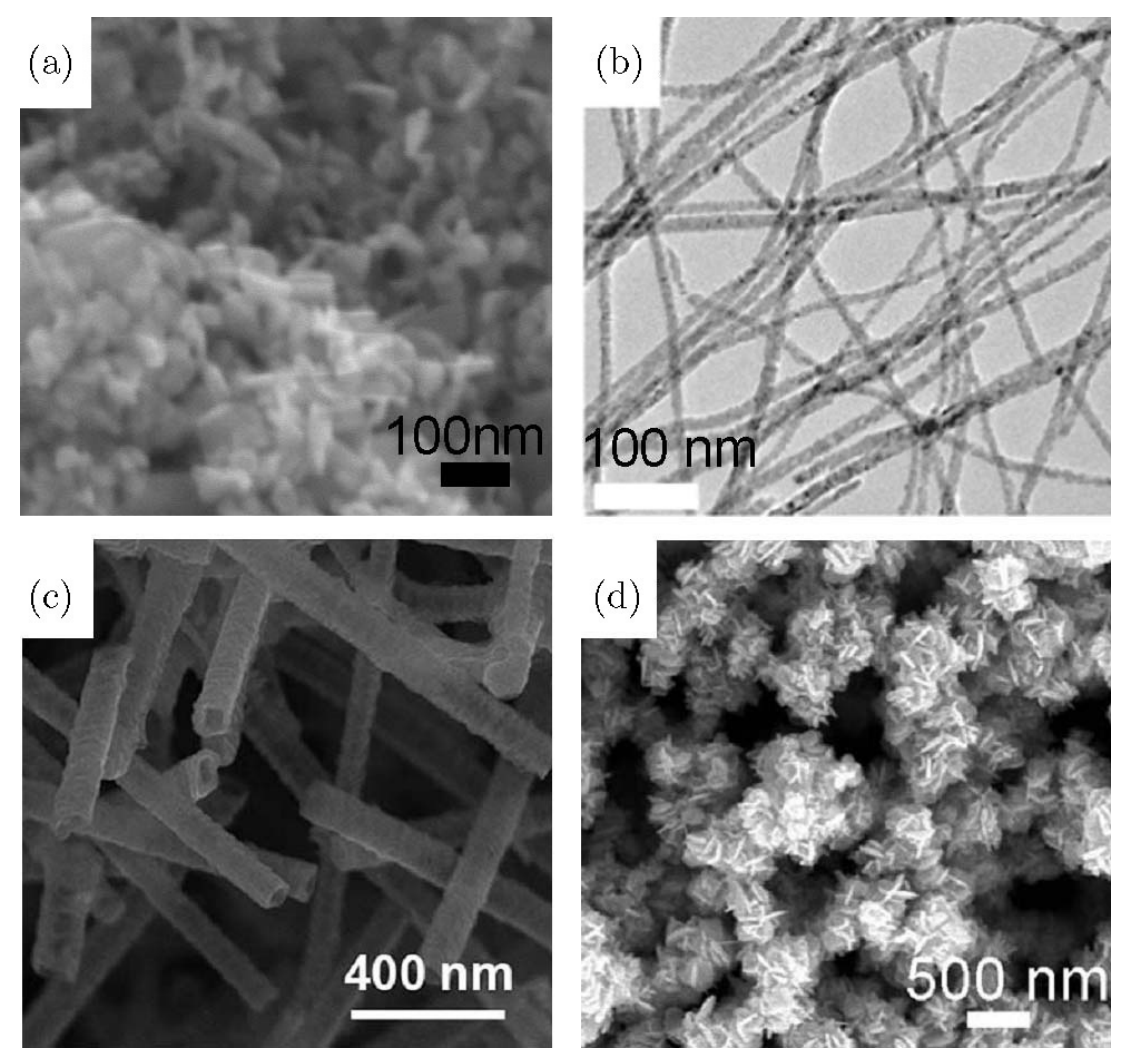

Fig. 4. Different morphologies of the (a) nanopowders (unpublished, given by Q H Jiang), (b) nanowire (reprinted with permission from Ref. 27. Copyright (2014) American Chemical Society), (c) nanotube (reproduced from Ref. 26 with permission from The Royal Society of Chemistry) and (d) nanoflower (reproduced from Ref. 28 with permission from The Royal Society of Chemistry) prepared via hydrothermal method.

frequency, the strong magnetic and electric field may force polar molecules (ethylene glycol) to realign and vibrate acutely. Powerful energies are generated from the inside of the materials because of the violent collision and friction between polar molecules. Thus, the green body is heated uniformly at an ultrafast heating rate. Up to now, only several compounds, such as $\mathrm{Bi}_{2} \mathrm{Te}_{3},{ }^{37-} \mathrm{Sb}_{2} \mathrm{Te}_{3}{ }^{39}$ and $\mathrm{Bi}_{2} \mathrm{Se}_{3}{ }^{40}$ were successfully synthesized by this microwave assisted method. This method may be extended to the synthesis of other TE material.

\subsection{A top-bottom approach}

Ball milling process can be used to grind materials into extremely fine powders for further process of coals, paints, or ceramics. If the rotation speed is increased to higher level, mixed powders are subjected to high-energy collision from the balls. This method, also called as mechanical alloying, already successfully produces almost all TE powders. ${ }^{41,42}$ In this process, the reaction can go on without high temperature environment. The powders are flattened from the collision of the balls and this micro-forging leads to plastic deformation. Thus, high-energy ball milling is also a process of mechanical activation. Cold welding may also occur and new phase can appear with the appearance of many defects and nanograins.
So it is an effective top-bottom approach to synthesize TE naonpowders. For example, nanostructured $n$-type Si80Ge20 alloy can be synthesized using high-energy ball milling combined with SPS. The sample has randomly oriented grains with an average size of 3-7 nm, as shown in Fig. $5{ }^{43}$ This method can continuously produce large scale nanopowders with low cost. Although interface contamination is a major problem, the samples consolidated from these ball milled powders still have excellent ZT value. ${ }^{44}$

Alternatively, melt spinning is another main process to obtain nanograins as a technique used for rapid cooling of liquids. A thin stream of liquid is dripped onto the wheel internally cooled by water or liquid nitrogen, causing rapid solidification. This technique is used to develop materials that require extremely high cooling rates on the order of $10^{4}-10^{7} \mathrm{~K} /$ s. Zheng et al. used melt spinning combined with SPS method to fabricate hierarchical structures $\mathrm{Bi}_{0.5} \mathrm{Sb}_{1.5} \mathrm{Te}_{3}$ with good TE properties (max ZT 1.22), ${ }^{45}$ whose hierarchical structure consists of particles ranging from $50 \mathrm{~nm}$ NPs to submicrometer grains (up to $20 \mu \mathrm{m}$ ). Other compound ribbons, such as $\mathrm{Bi}_{85} \mathrm{Sb}_{15},{ }^{46} \mathrm{Co}(\mathrm{SbGe})_{3},{ }^{47} \mathrm{Zn}_{x} \mathrm{Sb}_{3},{ }^{48} \mathrm{AgSbTe}_{2},{ }^{49}$ and $\mathrm{Si}-\mathrm{Ge},{ }^{50}$ are already prepared via this method. Meanwhile, this rapid quenching is helpful to get some metastabe phase such as $\mathrm{Al}_{6} \mathrm{Ge}_{5} \cdot{ }^{51}$ Although the span between the copper wheel and 

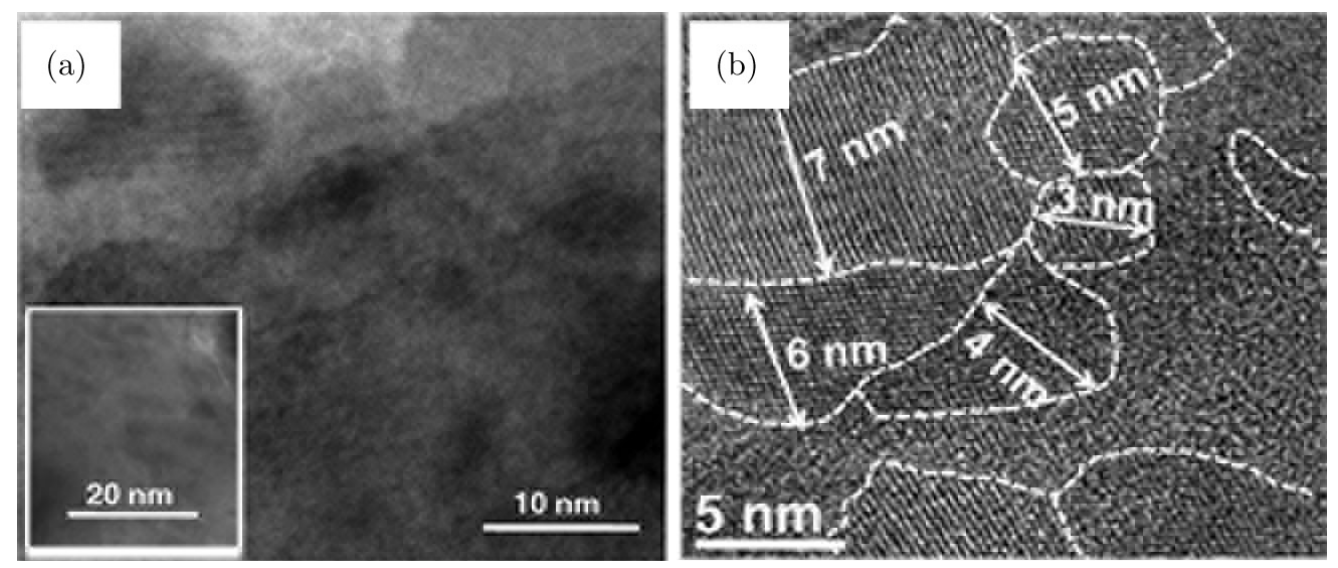

Fig. 5. HRTEM images of $\mathrm{Si}_{80} \mathrm{Ge}_{20}$ alloy showing (a) uniform ultra-fine densely packed microstructure, (b) distribution of different nanograins marked with dotted white lines. (reprinted with permission from Ref. 43. Copyright (2014) AIP Publishing).
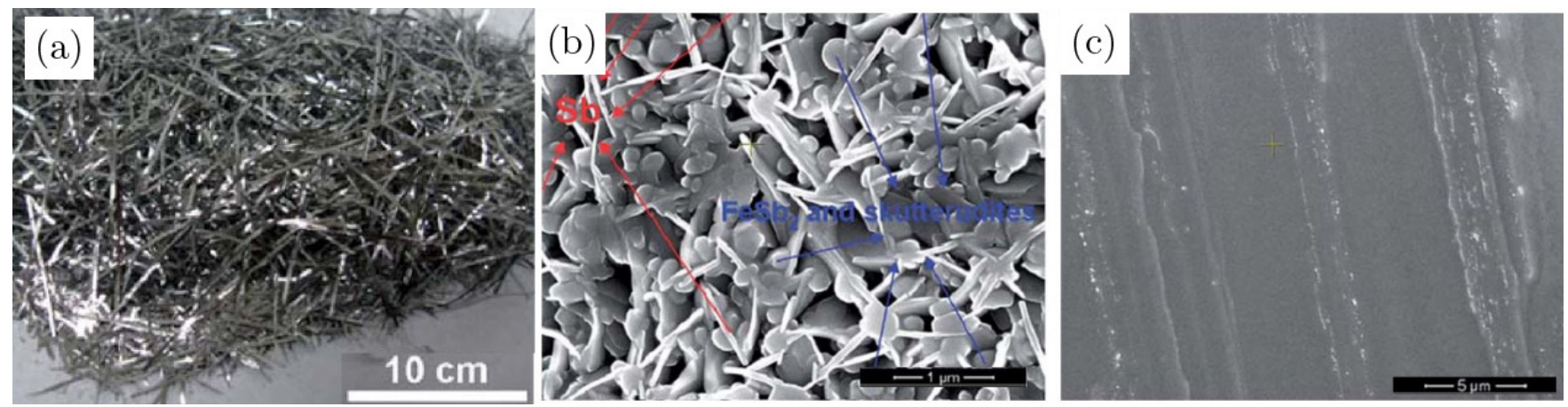

Fig. 6. The pictures of melt spun ribbons. (a) Ribbons, (b) Free surface and (c) contact surface (reproduced from Ref. 52 with permission from The Royal Society of Chemistry).

spray nozzle is only tens or hundreds of micrometers, there is still huge temperature difference in the ribbons. Due to this temperature difference, totally different micro-morphologies can be observed in very thin ribbons. There is flat amorphous surface and no grain structure is observed on the ribbon surfaces which contacted with rotating roller, while the opposite surface of the ribbon comprises clear nano- or micro-crystals, as shown in $\mathrm{CeFe}_{4} \mathrm{Sb}_{12}$ compounds (Fig. 6). ${ }^{52}$

\section{Microstructure Tailoring}

TE properties are sensitive to the microstructure due to different phonon scattering. Many different microstructures, such as anisotropic polycrystalline, hierarchical nanostructure and nanocomposites, can be tailored via several methods of synthesis and sintering process like hot-press or SPS. (In Sec. 5, these techniques will be discussed in detail).

\subsection{Anisotropic structures}

Dynamic hot forging via SPS process can easily fabricate high anisotropic structures for the compounds of layered crystal structures. Normally, good grain orientation is helpful in lowering the electrical resistivity and enhancing the TE power factor but with little influence on the Seebeck coefficient. Highly (001) oriented $\mathrm{Ca}_{3} \mathrm{Co}_{4} \mathrm{O}_{9}$ ceramics can exhibit large TE power, and the $\mathrm{ZT}$ value for La-doped $\mathrm{Ca}_{3} \mathrm{Co}_{4} \mathrm{O}_{9}$ sample can reach 0.26 at $975 \mathrm{~K} .{ }^{53}$ Via one-step SPS process, only $\mathrm{Bi}_{2} \mathrm{Te}_{3}$ compounds without orientation can be obtained. ${ }^{54,55}$ After hot forging, $\mathrm{Bi}_{2} \mathrm{Te}_{3}$ compounds with preferred orientation can be fabricated with enhanced ZT values. ${ }^{42,56}$ During hot forging process, the initial forged temperature should be confirmed carefully, else preferred orientation cannot be successfully achieved. Rapid superplastic deformation can lead to the sliding and alignment of the nanograins perpendicular to the pressing direction. Meanwhile, under optimized sintering temperature, rapid anisotropic growth in the $\mathrm{a}-\mathrm{b}$ plane will lead to a hierarchical microstructure with nanograins of $\sim 10 \mathrm{~nm}$ at the bottom level, the nanoflakes with the thickness of several tens nanometers at the intermediate level and the microsized flakes at the top level, as shown in Fig. $7 .{ }^{42}$

$\mathrm{BiCuSeO}$, a layered $\mathrm{ZrSiCuAs}$-like structure, is composed of alternately stacked $\left(\mathrm{Bi}_{2} \mathrm{O}_{2}\right)^{2+}$ insulating layers and $\left(\mathrm{Cu}_{2} \mathrm{Se}_{2}\right)^{2-}$ conducting layers along the $c$-axis, whose $\mathrm{ZT}$ value is highest among oxygen containing materials, as shown in Fig. 8. Many reports focused on how to improve its 

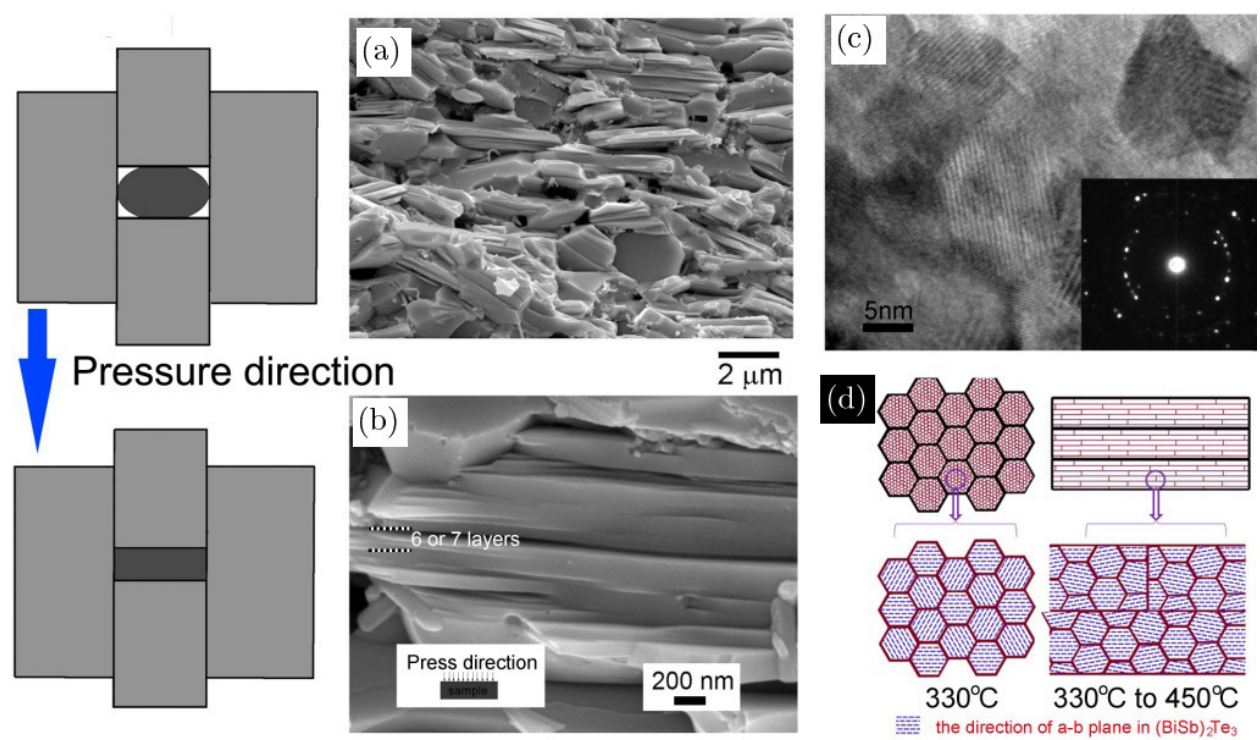

Fig. 7. (a) The schematic of hot forging, and (b) SEM pictures of hot forged $\mathrm{Bi}_{2} \mathrm{Te}_{3}$ compound, (c) high-solution TEM image, and microstructural diagrams of the samples before and after hot forging. (Reproduced from Ref. 42 with permission from The Royal Society of Chemistry).

ZT value via doping with various $\mathrm{di} / \mathrm{monovalent} \mathrm{ions}^{57-60}$ and also by $\mathrm{Cu}$-deficient self-doping. ${ }^{61}$ After hot forging, $\mathrm{BiCuSeO}$ compounds with anisotropic structure should have more excellent TE properties and a possible industrial application. $^{6}$

\subsection{Hierarchical nanostructure}

Hierarchical nanostructure has high grain boundaries density and direct transport pathways for charge carriers, while it can effectively scatter phonons with a very wide range of wavelengths. There are several reports on $\mathrm{Bi}_{2} \mathrm{Te}_{3}$ compounds with
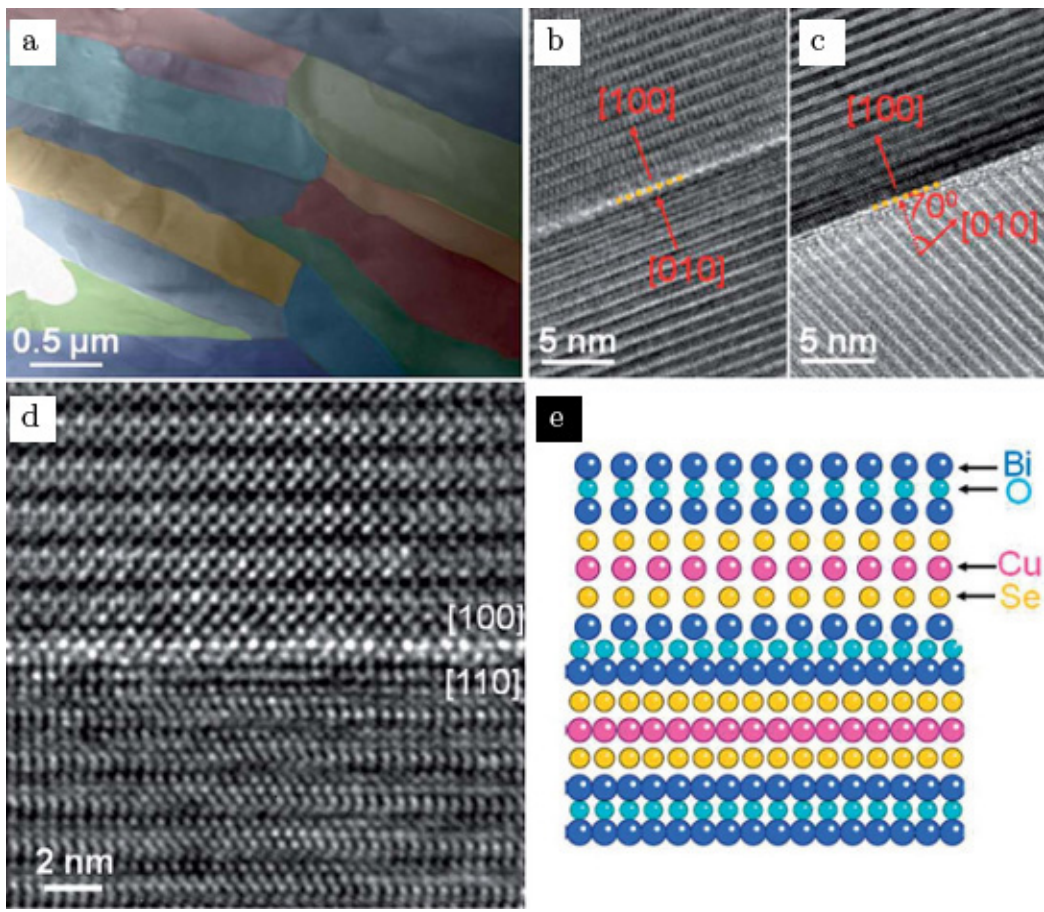

\section{e}

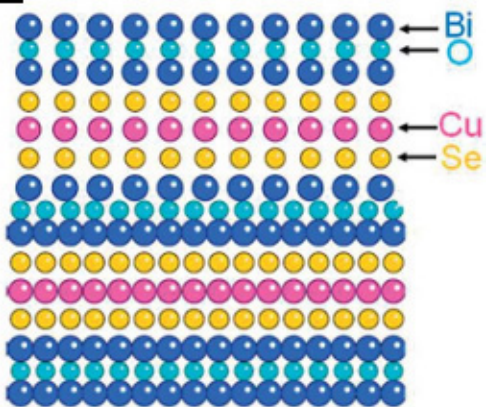

Fig. 8. Microstructures of the pristine BiCuSeO sample: (a) low magnification TEM image. (b) and (c) High resolution TEM images reveal two typical grain orientations. (d) The lattice image shows a good interface between two grains of the BiCuSeO sample. (e) Atomic model of the two grains based on [100] (top) and [110] (bottom) directions. (Reproduced from Ref. 6 with permission from the Royal Society of Chemistry). 

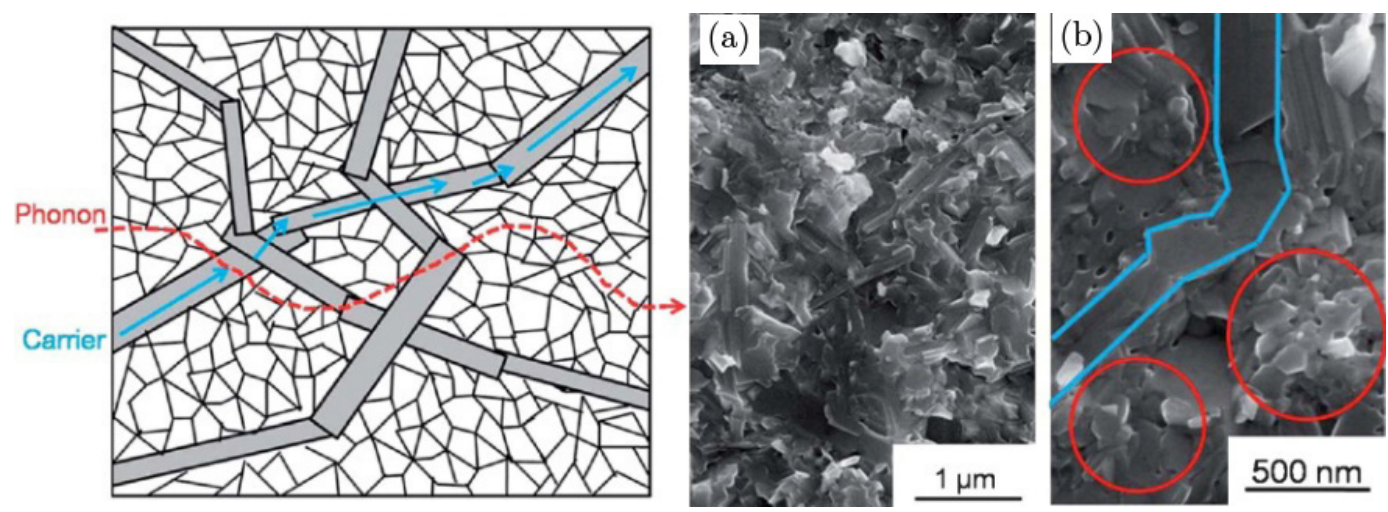

Fig. 9. (a) Design drawing of the composite-like microstructure in $\mathrm{Bi}_{2} \mathrm{~S}_{3}$ and (b) its FESEM images (reproduced from Ref. 34 with permission from the Royal Society of Chemistry).

this structure. Two types of $\mathrm{Bi}_{0.4} \mathrm{Sb}_{1.6} \mathrm{Te}_{3}$ powders with the same chemical compositions and different particle/grain-size differences were mixed by hand or ball milling process, then sintered via hot pressing or SPS to produce nano/microstructured composites. The as-prepared samples exhibit ultralow thermal conductivity $\sim 0.4 \mathrm{~W} /(\mathrm{m} \cdot \mathrm{K}),{ }^{62}$ which are attributed to strong phonon scattering by nanograin boundaries. A ZT value of 1.19 is obtained at $373 \mathrm{~K}$ with containing $40 \%$ nanograin powders, higher than that of the monolithic nanostructured sample. ${ }^{63}$

Ge et al. ${ }^{34}$ proposed another model as shown in Fig. 9, in which fine grains contribute to the low thermal conductivity, while strip-like grains with a rapid electron transport path contribute to the low electrical resistivity. Single crystal nanorods and nanopowders were synthesized via hydrothermal synthesis and mechanical alloying, respectively. After consolidation, the carrier mobility increased by more than two orders of magnitude (10wt.\% nanorods), but the thermal conductivity was just slightly increased, leading to double enhancement of ZT value.

\subsection{Superlattice structure}

A superlattice structure has a large density of states near the Fermi surface, which leads to a large Seebeck coefficient. Its high-density interfaces can greatly strengthen phonon scattering. ${ }^{64}$ Nanocomposites with similar structure can also be a promising approach to enhance ZT values of bulk TE materials. Cao et al. combined hydrothermal synthesis with hot pressing to prepare the bulk $\mathrm{Bi}_{2} \mathrm{Te}_{3} / \mathrm{Sb}_{2} \mathrm{Te}_{3}$ samples with superlattice-like layered structure, as shown in Fig. 10. The thickness of the nanolayers is about between $5 \mathrm{~nm}$ and $50 \mathrm{~nm}$. This laminated structure can improve ZT value to $1.47 .^{65}$ However, there are little reports about TE properties of particular nanocomposites which may also have excellent ZT values after realizing the clear interfaces between two phases, like $\mathrm{InSe} / \mathrm{In}_{4} \mathrm{Se}_{3}$ composite. ${ }^{66}$

\subsection{Core-shell structure}

The differential effective medium method was used to theoretically calculate the lattice thermal conductivity of nanocomposites comprising core-shell particles. Inter-particle boundary scattering in addition to intra-particle boundary scattering in core-shell structure can further reduce thermal conductivity of nanocomposites. ${ }^{67}$ Several chemical methods, such as sol-gel or hydrothermal method, were adopted to synthesis this core-shell structure powders and SPS was used to inhibit the diffusions between core and shell part via rapid
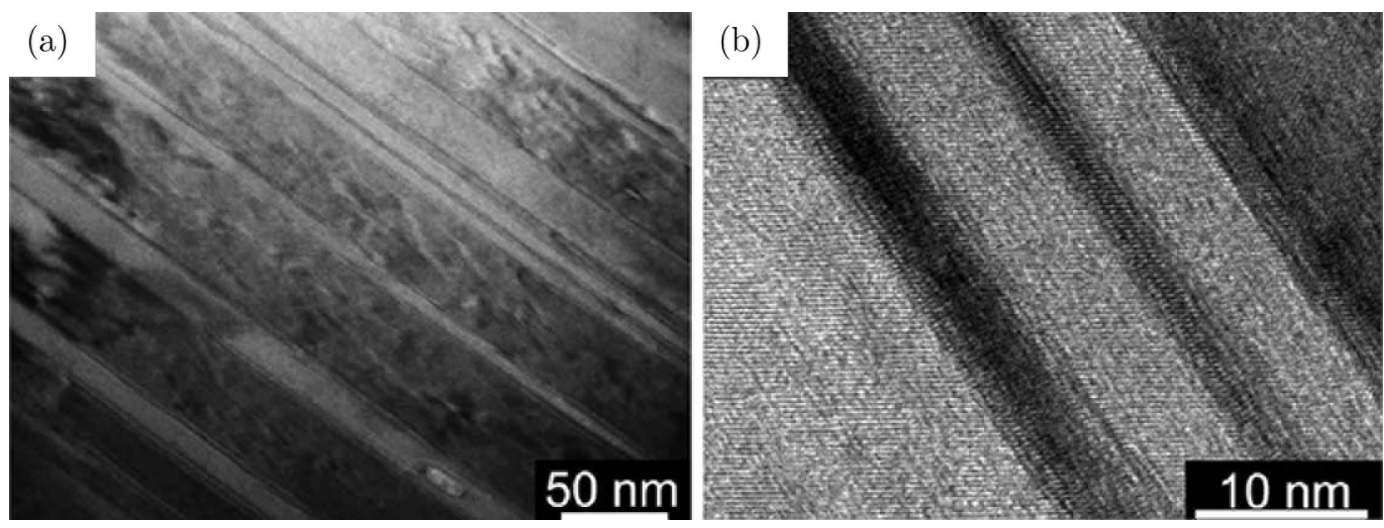

Fig. 10. Laminated nanostructure of bulk $\mathrm{Bi}_{2} \mathrm{Te}_{3} / \mathrm{Sb}_{2} \mathrm{Te}_{3}$ samples. (a) TEM image; (b) HTEM image. (Reprinted with permission from Ref. 65. Copyright (2014) AIP Publishing). 
consolidation. Some groups independently fabricated several composites with different compounds, such as $\mathrm{C} @ \mathrm{Sb}_{2} \mathrm{Te}_{3},{ }^{68}$ $\mathrm{TiO}_{2} @ \mathrm{TiC}_{0.5} \mathrm{O}_{0.5}{ }^{69}$ and PbTe@PbS. ${ }^{70}$ For example, PbS$\mathrm{PbTe}$ core-shell composites synthesized via hydrothermal method have an enhanced power factor, compared to that of pure $\mathrm{PbS}^{70}$ Besides, Fu et al. fabricated a core-shell microstructure in $\mathrm{Yb}_{0.2} \mathrm{Co}_{4} \mathrm{Sb}_{12} \mathrm{Yb}$ with Ni-rich nanograin shells via thermal diffusion of well dispersed Ni NPs. The sample with this special structure has maximum $\mathrm{ZT}$ value of 1.07 at $723 \mathrm{~K}^{71}$

\subsection{Nanocomposites with second phase}

There are two mechanisms to enhance $\mathrm{ZT}$ value of TE nanocomposites with second phase: (1) the addition of nanoinclusions generally reduced the lattice thermal conductivity; (2) the energy filtering effect at the matrix-nanoinclusion interfaces. ${ }^{72}$ For example, bulk $\mathrm{Bi}_{2} \mathrm{Te}_{3}$ with silicon nanocrystallites have a $50 \%$ drop in thermal conductivity and a simultaneous enhancement in the Seebeck coefficient. ${ }^{73}$ Nano-SiC dispersion in BiSbTe alloys can simultaneously ameliorate the TE and mechanical properties. ${ }^{74}$ Xiao et al. utilized thermal decomposition of $\beta-\mathrm{Zn}_{4} \mathrm{Sb}_{3}$ addition and dual nanoinclusions of $\mathrm{Zn}$ and $\mathrm{ZnSb}$ can be introduced simultaneously. Phonon thermal conductivity was greatly reduced by the $\mathrm{ZnSb}$ and $\mathrm{Zn}$ nanoinclusions and a maximum $\mathrm{ZT}$ of 1.44 has been achieved at $423 \mathrm{~K} .{ }^{75}$ The introduction of Ag NPs put into $\mathrm{TiO}_{2}$ bulk ceramic can remarkably increase the Seebeck coefficient on account of the electron filtering effect and ZT value was increased by about two-fold. ${ }^{35}$

Meanwhile, some NPs can simultaneously optimize at least two TE parameters of electrical conductivity, Seebeck coefficient and thermal conductivity. For example, mesoporous silica $^{76}$ or yttria stabilized zirconia ${ }^{77}$ addition with a low thermal conductivity also enhances the electrical conductivity significantly and keeps Seebeck coefficient independent, thus, enhancing the ZT value. For example, well-dispersed $\mathrm{AgSbTe}_{2}$ nanoinclusions on the $\mathrm{Yb}_{0.2} \mathrm{Co}_{4} \mathrm{Sb}_{12}$ matrix grain boundaries can simultaneously optimize all three parameters. In particular, between $6 \mathrm{wt} . \%$ and $8 \mathrm{wt} . \%$ of nanoinclusions, there are several shapes of inclusions such as NPs, nanoplates and coating, yielding a room temperature figure of merit ZT $0.51 .^{78}$

\section{Consolidation Techniques}

There are many consolidation techniques, such as melting process, hot-press sintering, microwave sintering, hot isostatic pressing (HIP) sintering, laser sintering and SPS which may fabricate the TE bulk and modules. Traditional melting process is the cheapest and has been widely used in industry up to now. However, it is very difficult to fabricate nanostructured bulk via melting process or traditional solid sintering. Up to now, hot pressing or SPS process is normally used to tailor the microstructure of TE materials, except in situ synthesis.

\subsection{Hot-press sintering}

Current main sintering techniques to obtain nanostructured bulk are all based on pressure sintering, such as hot-press sintering and SPS process. Both processes utilize a uniaxial load to a powder compact during sintering process in order to decrease the sintering temperature and improve the density. For hot-press sintering, it will take $2 \mathrm{~h}$ or more to realize the consolidation, and this process also consumes a huge amount of energy similar to melting process. Yang et al. developed a new microwave-activated hot pressing. The microwave energy was simultaneously applied on the pre-sintered powders under an axial mechanical load. As a result, high density of the nanostructured BiSbTe samples can be realized at lower temperature, and minimum lattice thermal conductivity of $0.41 \mathrm{~W} /(\mathrm{m} \cdot \mathrm{K})$ and a maximum $\mathrm{ZT}$ value of 1.04 are obtained at $325^{\circ} \mathrm{C}^{79}$

\subsection{Spark plasma sintering}

SPS is a rapid sintering method (e.g., $500^{\circ} \mathrm{C} / \mathrm{min}$ ) that enables consolidation of powders at comparatively low temperatures. This method was first used to sinter the metal ${ }^{80}$ or ceramic $^{81}$ with rapid sintering speed. It can achieve high densification with minimal grain growth, and is therefore a useful method for fabricating bulk nanoceramics. Also, grainorientated layer-textured ceramics have been successfully fabricated via this advanced technology, such as the Aurivillius phase $\mathrm{CaBi}_{2} \mathrm{Nb}_{2} \mathrm{O}_{9},{ }^{82}$ and layered structured compounds. ${ }^{83}$ Due to its rapid consolidation at lower temperature, it is very useful in the fabrication of TE bulk with tailored microstructure. Now almost all the bulk TE materials with highest ZT values are fabricated via SPS process.

Some publications show that the textured layer structure can lead to significantly increased in-plane electrical conductivity and increased ZT. Residual stresses introduced into the TE materials from SPS's rapid sintering can change the conductivity properties and lead to new physical mechanism. Therefore, SPS is a good exploratory method to fabricate TE materials with higher ZT. Delaizir et al. used three processes: $\mathrm{HIP}\left(480^{\circ} \mathrm{C}\right.$ for $\left.60 \mathrm{~min} / 150 \mathrm{MPa}\right)$, microwave sintering (400 to $420^{\circ} \mathrm{C}$ for $10 \mathrm{~min}$ ) and SPS (SPS) $360^{\circ} \mathrm{C}$ for $5 \mathrm{~min} /$ $50 \mathrm{MPa}$ ) to sinter $p$-type ball milled $\mathrm{Bi}_{2} \mathrm{Te}_{3}$ nanopowders. Although HIPed and SPSed samples have high density and similar microsture, highest $\mathrm{ZT}$ values are obtained via microwaves $(\mathrm{ZT}=0.74$, low compactness $(90 \%))$ and by SPS $(Z T=0.68)$ because of the difference in charge carriers concentration and microstructure difference. ${ }^{84}$

Osvenskiy et al. ${ }^{28}$ would like to understand the relationship between crystallite size of $\mathrm{Bi}_{2} \mathrm{Te}_{3}$ and sintering temperature. The crystallite size grows with increasing temperature from $250^{\circ} \mathrm{C}$ to $400^{\circ} \mathrm{C}$ and decreases at temperatures from $400^{\circ} \mathrm{C}$ to $500^{\circ} \mathrm{C}$. They explained this phenomenon as follows: the sample at $250^{\circ} \mathrm{C}$ leads to collective recrystallization under low defects mobility; at $300-400^{\circ} \mathrm{C}$, 
the grains continue to grow and large twins appear; at $450^{\circ} \mathrm{C}$, as the defect mobility increases, recrystallization occurs and new grains on the grain boundaries precipitate faster than the old grains grow.

For nearly all the TEs, highest ZT values are achieved via SPS, although some groups have different results for the same recipe and condition such as $\mathrm{Bi}_{2} \mathrm{Te}_{3}$ compounds whose $\mathrm{ZT}$ value can be from 0.7 to 1.8 . This difference may be from the special characteristics of SPS. Normally, during the consolidation cycle of the SPS, the experimental parameters of temperature, applied pressure, current, voltage and sample displacement (shrinkage) are exactly recorded continuously by the SPS system software. However, the exact conditions in the sample cannot be monitored because of its localized internal heat generation mechanisms.

In the sintering process, a primary heating source is Joule heating. ${ }^{85}$ Besides the local part of powders, there are several sources: graphite dies, punches, the foils between punches and dies, the interfaces between foils and dies, foils and punches, or powders and punches, as shown in Fig. 11. Since contact resistances are available and very harmful to the homogenous sintering, excellent contacts should be kept between these parts in order to homogenous temperature distribution, or ultra high local temperature will appear near the gaps. Ideally, the maximum resistance to the electric path is from particle-particle contacts. However, because of the aggregation of powders and nonhomogenous press distribution in the die, plasma discharge will appear near the necks or gaps of powders or aggregates, and may be dominant in many heating sources in the initial and middle processes. As a result, the initial density of green body is a key parameter which can affect the exact inner temperature. Meanwhile, large aggregation of powders should be avoided in order to get homogenous distribution of temperature. If there are some pores inside, there will be ultra high temperature we cannot measure or estimate. In order to understand the phenomenon near the gaps in the SPS process, $\mathrm{BiFeO}_{3}$ powders with some organics inside were sintered via SPS method. $\mathrm{BiFeO}_{3}$ is an oxide with the decomposition temperature of about $900^{\circ} \mathrm{C}$ which is higher than most TE compounds. As shown in Fig. 12(a), dense $\mathrm{BiFeO}_{3}$ sintered at $600^{\circ} \mathrm{C}$ for $1 \mathrm{~min}$ has narrow grain size distribution of $0.6 \mu \mathrm{m}$. There is a pore inside the green body from the volatilization of the organics. A perfect $\mathrm{Bi}-\mathrm{Fe}-\mathrm{O}$ crystal with the length of $2 \mu \mathrm{m}$ grows from the surface of the pore inside (Fig. 12(b)), which indicates there is ultra high temperature near the gaps. As a result, homogenous particle size distribution of the powders without aggregation is key to control the microstructure and plays a significant role in getting reliable TE properties. One the other hand, the brittle rupture of the specimens should be avoided during the heating process for hot forging.

Meanwhile, there are some other very important parameters which will obviously affect the distribution of temperature distribution, such as the heating rate (from $10 \mathrm{~K} / \mathrm{min}$ to $200 \mathrm{~K}$ ), the measured spot on the die, die geometry (wall thickness, die height, sample diameter, etc.), and heat loss by radiation. ${ }^{86,87}$ For example, electric field across the powders can be significantly increased by decreasing die wall thickness or extending off-time of the DC pulsed current, as shown in Fig. 13. The current density and temperature distribution in the sample depend on the electrical and thermal conductivity,

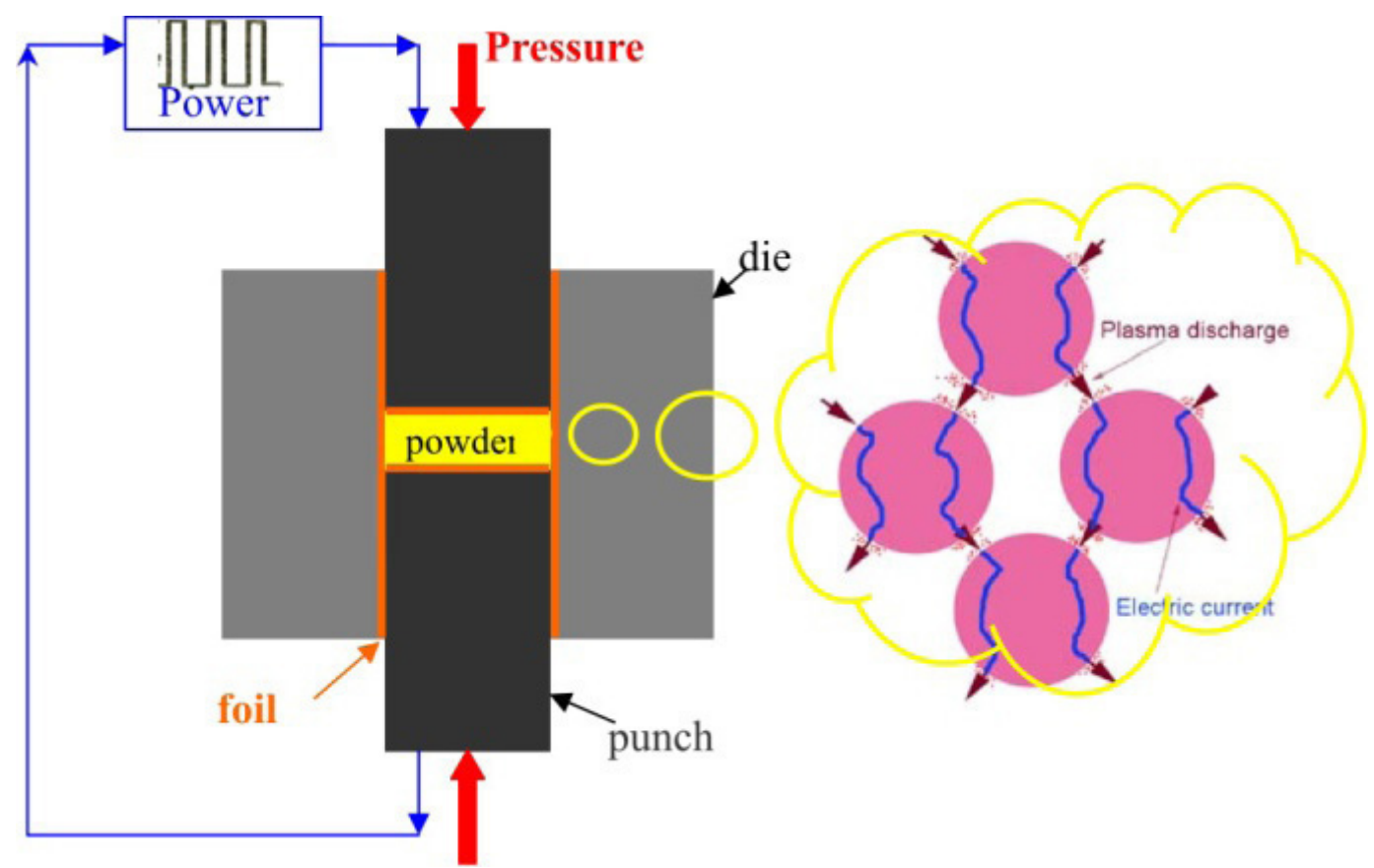

Fig. 11. The scheme picture of SPS machine. 

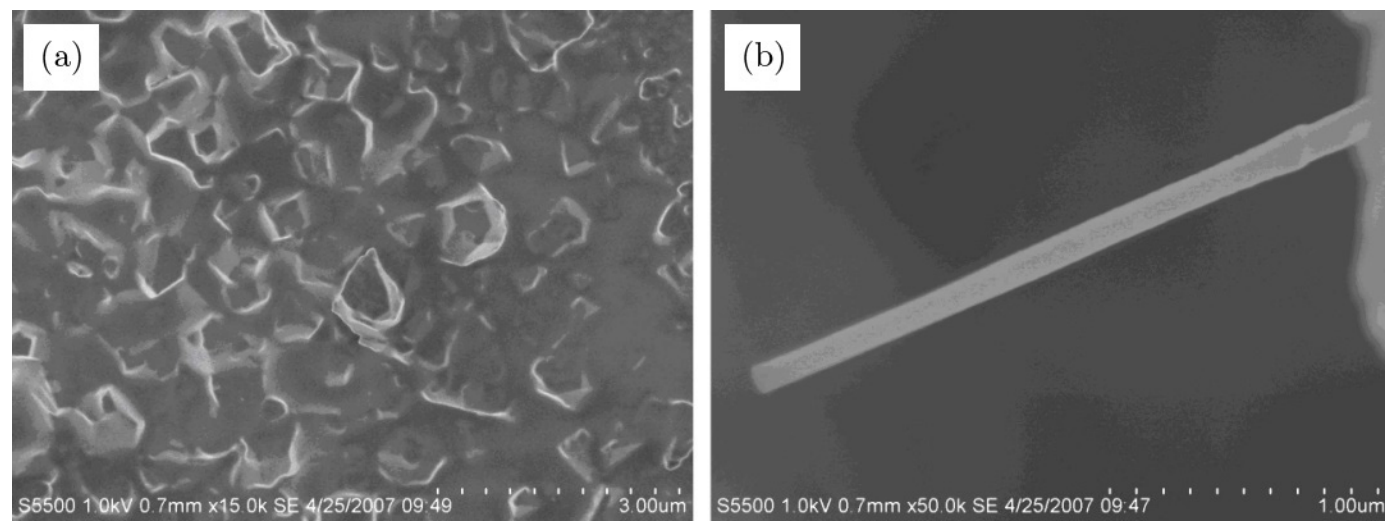

Fig. 12. SEM pictures of (a) dense $\mathrm{BiFeO}_{3}$ oxide and (b) a crystal grown from the gap in the sample (provided by Jiang and Zhijian Shen, Stockholm University).

respectively. ${ }^{88}$ Since TE materials should have lower thermal conductivity, these field distributions will have more obvious effect on the temperature field, leading to nonhomogenous sintering.

\subsection{Melting process and unequilibrium solidification process}

Traditional melting process method has been widely used to produce metallic ingot for industrial application. Normally, second phases or micro-pores will appear due to inhomogeneous solidification in this process. So some additive agents or rotatory furnaces are used in melting process for higher ZT values or better mechanical properties. As we know, single crystals for different compounds would have excellent or best TE properties. ${ }^{90}$ The main challenge is how to get large size single crystal for industry application with low cost and high efficiency. On the other hand, during the melting process, some external fields, such as magnetic field, can affect liquid metal motion and nucleation, and lead to unequilibrium crystallization. This microstructure tailoring from external fields can improve the thermoelectric properties due to multiple mechanisms. For example, external high magnetic field can activate the nucleation of $\mathrm{Bi}_{0.5} \mathrm{Sb}_{1.5} \mathrm{Te}_{3}$ alloys, and lead to the formation of BSTII nanorods, as shown in Fig. 14. Meanwhile, $c$-axis alignment of $\mathrm{Bi}_{0.5} \mathrm{Sb}_{1.5} \mathrm{Te}_{3}$ results in the crystal reorientation. At $2 \mathrm{~T}$, an enhanced $\mathrm{ZT}$ value of 1.71 at $323 \mathrm{~K}$ is obtained. ${ }^{91}$ Up to now, there are no reports on the effect of other

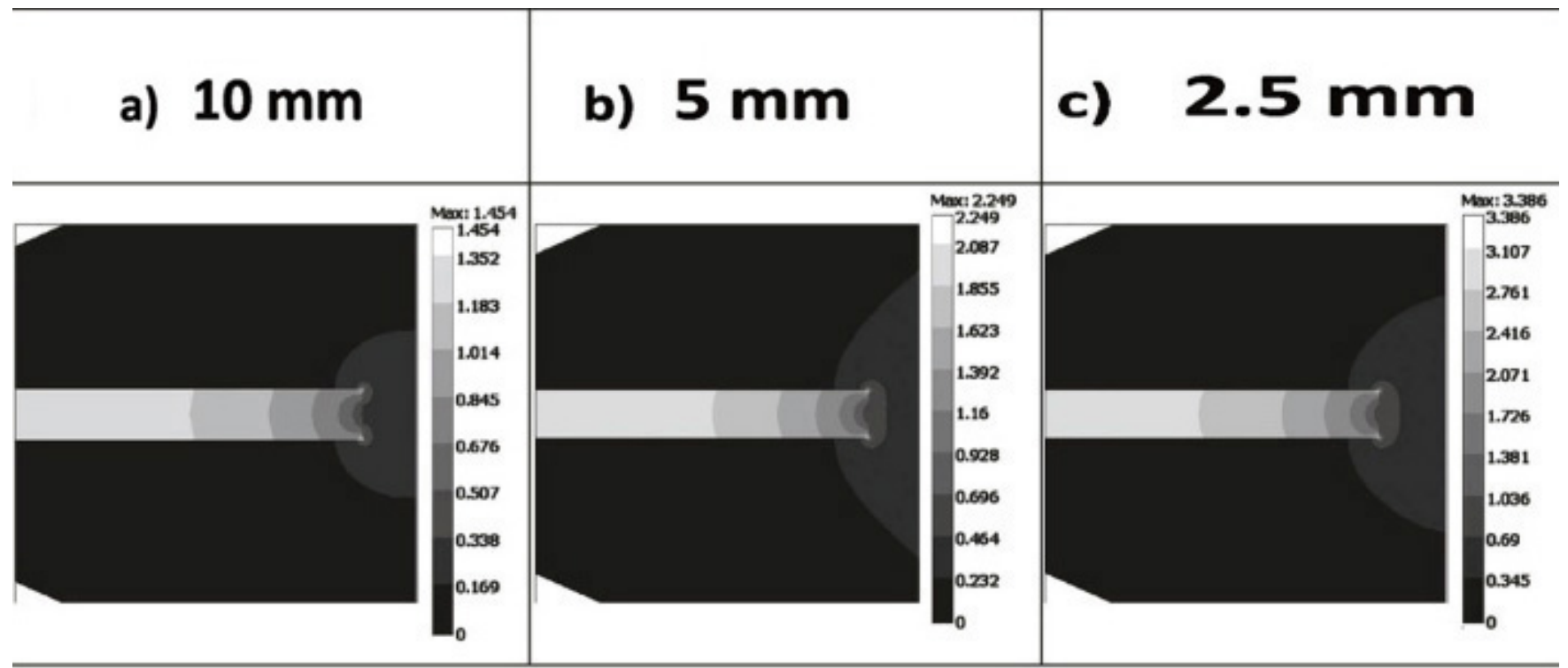

\section{Electric field $\mathbf{V} / \mathrm{cm}$}

Fig. 13. FEM model of electric field $(\mathrm{V} / \mathrm{cm})$ across $3 \mathrm{Y}-\mathrm{TZP}$ sample. The electric fields are plotted during the dwelling for die thickness of (a) $10 \mathrm{~mm}$, (b) $5 \mathrm{~mm}$ and (c) $2.5 \mathrm{~mm} .{ }^{89}$ 

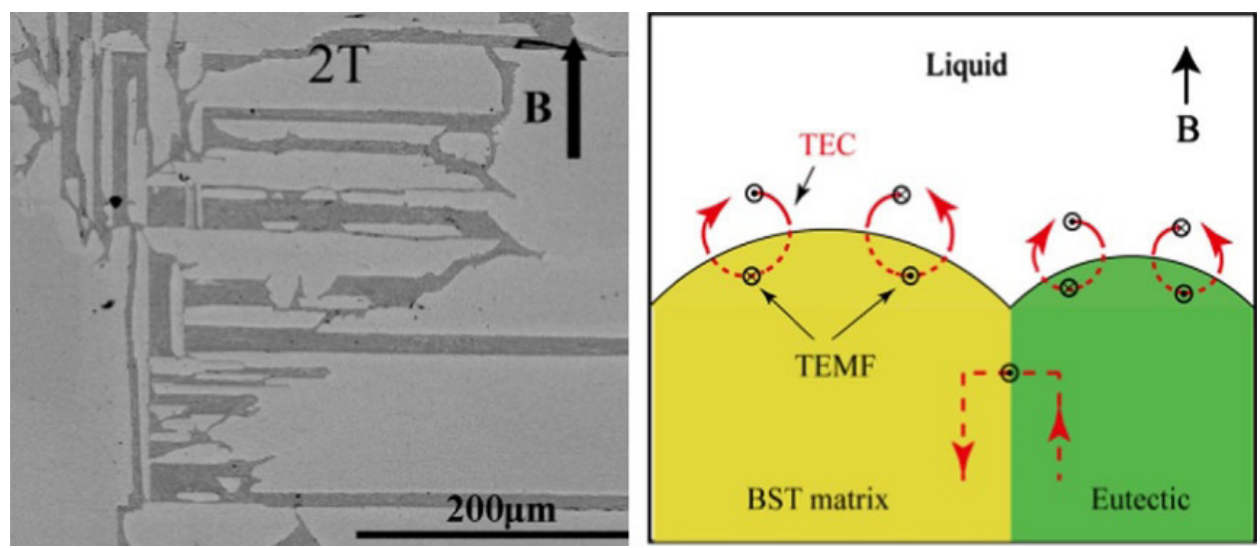

Fig. 14. ESEM images of the cross-section parallel to magnetic field direction of the samples prepared under $2 \mathrm{~T}$ (left), and Schematic illustration of TE current (TEC) and TE magnetic force (TEMF) in the vicinity of the solidification front (right). ${ }^{91}$

external fields, such as microwave field and alternating electric field on the solidification of TE compounds which may give us some pleasurable results in future.

\subsection{Laser sintering}

Laser sintering may be used to directly assemble TE modules from the powders as a 3D printing process. Wu et al. ${ }^{92}$ prepared $\beta$ - $\mathrm{FeSi}_{2}$-based TE alloy via laser sintering for the first time. Milled powders were cold pressed into a plate with $\Phi 10 \mathrm{~mm} \times 5 \mathrm{~mm}$, and placed into laser sintering furnace (power density on the surface is about $442.3 \mathrm{~W} / \mathrm{cm}$ for $90 \mathrm{~s}$ ). These samples exhibit homogeneous microstructure with average grain size of less than $5 \mu \mathrm{m}$. A maximum Seebeck coefficient at room temperature could reach $115 \mu \mathrm{V} / \mathrm{K}$. Stoib et $a l .{ }^{93}$ also fabricated thin films of Ge via short-pulse lasersintering of Ge NPs in vacuum. A pulsed Nd:YAG laser at $532 \mathrm{~nm}$ with a pulse duration of 5-7 ns at a repetition rate of $10 \mathrm{~Hz}$ was used. A macroporous film was obtained with scanning velocity of $0.5 \mathrm{~mm} \cdot \mathrm{s}$. However, there are no exact TE properties reported up to now. The main challenge is the precise control of the laser power and exact temperature at moderate temperature range under inner environment, which is the key parameter to keep the balance between melting process and initial growth of the grains.

\section{Outlook}

The TE properties of most compounds can be obviously increased via nanostructuring from reduced thermal conductivity by the selective scattering of phonons and enhanced Seebeck coefficient by modification of the density of the states. Most chemical processes and consolidation techniques were used to fabricate bulk TE materials with nanostructure. In this paper, we reviewed and summarized recent progresses on the fabrication and microstructure tailoring of nanostructured materials in past several years. The realization of nanostructures has received ever-increasing attention and has been extensively studied, and the TE performance ZT can be significantly increased by $50 \%$ to $100 \%$. Despite vast efforts on this microstructure tailoring being devoted, the studies as a promising way to increase ZT values of TE materials are still at a relatively initial stage. Unlike traditional structural materials, many fundamental and technical issues remain to be further investigated, which may include the following.

(1) More attention should be paid on synthesis of nanostructured particles on a large scale with low cost, which can lead to competitive commercial applications of TE materials facing industry and daily life. The nanostructures of traditional metals such as aluminum, copper and magnesium were successfully realized for industrial applications, and similar techniques ${ }^{94,95}$ may be used to fabricate the nanostructure in TE compounds.

(2) Since microstructure morphology of TE materials is much important to the transport properties, steerable structure tailoring of grain size or shape is beneficial to obtain higher ZT values. Before a good understanding on boundaries effect, it is needed to understand phase diagrams and related defect theory and quantify the effect of defects on the transport properties of TE compounds.

(3) In SPS, as a main consolidation technique, local temperature field of TE specimens should be well studied. For one exact TE compounds, nonhomogenous field distribution should be avoided, so it is necessary to maximize our knowledge about sintering mechanism of semiconductors during SPS process and enable us to determine parameters for reliable optimization of the process. Meanwhile, surface modification of spark plasma on the particles may have a great effect on TE properties, and its study is still at an infant step.

(4) Most TE specimens with good ZT value were fabricated via SPS technique, which may have good potential applications for industry. More attention should be paid to new consolidation techniques to rapidly densify the powders with lower cost or more effectively tailor the 
microstructure. For example, selective laser sintering and inkjet $3 \mathrm{D}$ printing can be two powerful and versatile techniques to fabricate the TE modules in precise geometry using computer aided design and manufacturing. It is also interesting to combine powder metallurgy and microwave or plasma annealing to realize repaid production of modules having nanostructured morphology with low cost. For this purpose, more understanding on the diffusion and sintering mechanism on the atomic level of TE compounds is needed.

\section{Conflicts of Interest}

The authors declare no conflict of interest.

\section{Acknowledgments}

This work was supported by the National Natural Science Foundation of China (Grant Nos. 51272080, 51572098 and 51472043), the National Basic Research Program of China (Grant No. 2013CB632500), the Natural Science Foundation of Hubei province (Grant No. 2015CFB432) and the Open Fund of State Key Laboratory of Advanced Technology for Materials Synthesis and Processing, Wuhan University of Technology (Grant No. 2013-KF-3).

\section{References}

${ }^{1}$ W. He, G. Zhang, X. X. Zhang, J. Ji, G. Q. Li and X. D. Zhao, Recent development and application of thermoelectric generator and cooler, Appl. Energy 143, 1 (2015).

${ }^{2}$ M. V. Frank, Probabilistic analysis of the inadvertent reentry of the Cassini spacecraft's radioisotope thermoelectric generators, Risk Anal. 20, 251 (2000).

${ }^{3}$ S. Su, T. Liu, Y. Wang, X. Chen, J. Wang and J. Chen, Performance optimization analyses and parametric design criteria of a dye-sensitized solar cell thermoelectric hybrid device, Appl. Energy 120, 16 (2014).

${ }^{4}$ Y. Liu, S. C. Yang, B. Guo and C. Deng, Numerical analysis and design of thermal management system for lithium ion battery pack using thermoelectric coolers, Adv. Mech. Eng. 8, 852712 (2014).

${ }^{5}$ C. Wan, Y. Wang, N. Wang, W. Norimatsu, M. Kusunoki and K. Koumoto, Development of novel thermoelectric materials by reduction of lattice thermal conductivity, Sci. Technol. Adv. Mater. 11, 044306 (2010).

${ }^{6}$ L. D. Zhao, J. Q. He, D. Berardan, Y. H. Lin, J. F. Li, C. W. Nan and N. Dragoe, BiCuSeO oxyselenides: New promising thermoelectric materials, Energy Environ. Sci. 7, 2900 (2014).

${ }^{7}$ J. F. Li, W. S. Liu, L. D. Zhao and M. Zhou, High-performance nanostructured thermoelectric materials, NPG Asia Mater. 2, 152 (2010).

${ }^{8}$ W. J. Xie, A. Weidenkaff, X. F. Tang, Q. J. Zhang, J. Poon and T. M. Tritt, Recent advances in nanostructured thermoelectric half-Heusler compounds, Nanomaterials 2, 379 (2012).

${ }^{9}$ G. Li, J. Y. Yang, Y. Xiao, L. W. Fu, J. Y. Peng, Y. Deng, P. W. Zhu and H. X. Yan, Effect of Fe substitution on thermoelectric properties of $\mathrm{Fe}_{x} \mathrm{In}_{4-x} \mathrm{Se}_{3}$ Compounds, J. Electron. Mater. 42, 675 (2013).

${ }^{10}$ B. Zhan, J. L. Lan, Y. C. Liu, Y. H. Lin, Y. Shen and C. W. Nan, High Temperature thermoelectric properties of Dy-doped $\mathrm{CaMnO}_{3}$ ceramics, J. Mater. Sci. Technol. 30, 821 (2014).

${ }^{11} \mathrm{~S}$. Quetel-Weben, R. Retoux and J. G. Noudem, Thermoelectric $\mathrm{Ca}_{0.9} \mathrm{Yb}_{0.1} \mathrm{MnO}_{3-\delta}$ grain growth controlled by spark plasma sintering, J. Eur. Ceram. Soc. 33, 1755 (2013).

${ }^{12}$ M. Anis-ur-Rehman, S. H. Abbasi and Z. Fatimatuz, Synthesis and development of thermoelectric properties in layered $\mathrm{Bi}_{2} \mathrm{~A}_{2-}$ $\mathrm{CoO}_{6}$, J. Supercond. Novel Magn. 28, 1029 (2015).

${ }^{13}$ D. Li, R. Li, X. Y. Qin, C. J. Song, H. X. Xin, L. Wang, J. Zhang, G. L. Guo, T. H. Zou, Y. F. Liu and X. G. Zhu, Co-precipitation synthesis of nanostructured $\mathrm{Cu}_{3} \mathrm{SbSe}_{4}$ and its $\mathrm{Sn}$-doped sample with high thermoelectric performance, Dalton Trans. 43, 1888 (2014).

${ }^{14}$ D. Li, X. Y. Qin, Y. F. Liu, C. J. Song, L. Wang, J. Zhang, H. X. Xin, G. L. Guo, T. H. Zou, G. L. Sun, B. J. Ren and X. G. Zhu, Chemical synthesis of nanostructured $\mathrm{Cu}_{2} \mathrm{Se}$ with high thermoelectric performance, $R S C A d v$. 4, 8638 (2014).

${ }^{15}$ M. Salavati-Niasari and M. Bazarganipour, Organic-assisted nanosized antimony telluride prepared by co-precipitation reductive route, J. Cluster Sci. 23, 503 (2012).

${ }^{16}$ W. W. Zhou, J. X. Zhu, D. Li, H. H. Hng, F. Y. C. Boey, J. Ma, H. Zhang and Q. Y. Yan, Binary-phased nanoparticles for enhanced thermoelectric properties, Adv. Mater. 21, 3196 (2009).

${ }^{17}$ M. Nagabhushanam, E. Nagabushan, D. J. Prakash, B. Rajam and K. Yadaiah, Growth, characterization and transport properties of $\mathrm{Pb}_{x} \mathrm{Zn}_{1-x} \mathrm{~S}$ mixed crystals, Bull. Mater. Sci. 32, 109 (2009).

${ }^{18}$ D. Li, R. Li, X. Y. Qin, J. Zhang, C. J. Song, L. Wang and H. X. Xin, Co-precipitation synthesis of $\mathrm{Sn}$ and/or $\mathrm{S}$ doped nanostructured $\mathrm{Cu}_{3} \mathrm{Sb}_{1-x} \mathrm{Sn}_{x} \mathrm{Se}_{4-y} \mathrm{~S}_{y}$ with a high thermoelectric performance, Cryst. Eng. Comm. 15, 7166 (2013).

${ }^{19}$ M. Saleemi, M. S. Toprak, S. H. Li, M. Johnsson and M. Muhammed, Synthesis, processing, and thermoelectric properties of bulk nanostructured bismuth telluride $\left(\mathrm{Bi}_{2} \mathrm{Te}_{3}\right)$, J. Mater. Chem. 22, 725 (2012).

${ }^{20}$ Q. H. Jiang, A. Mei, Y. H. Lin, C. W. Nan and Z. J. Shen, Ferroic properties of highly dense multiferroic $\mathrm{Bi}_{1-x} \mathrm{La}_{0.05} \mathrm{~Tb}_{x} \mathrm{FeO}_{3}$ ceramics via sheltered spark plasma sintering, J. Am. Ceram. Soc. 91, 2189 (2008).

${ }^{21}$ P. P. Shang, B. P. Zhang, J. F. Li and N. Ma, Effect of sintering temperature on thermoelectric properties of La-doped $\mathrm{SrTiO}_{3}$ ceramics prepared by sol-gel process and spark plasma sintering, Solid State Sci. 12, 1341 (2010).

${ }^{22}$ N. Y. Wu, T. C. Holgate, N. V. Nong, N. Pryds and S. Linderoth, High temperature thermoelectric properties of $\mathrm{Ca}_{3} \mathrm{Co}_{4} \mathrm{O}_{9+\delta}$ by auto-combustion synthesis and spark plasma sintering, J. Eur. Ceram. Soc. 34, 925 (2014).

${ }^{23}$ K. Agilandeswari and A. R. Kumar, Synthesis, characterization, temperature dependent electrical and magnetic properties of $\mathrm{Ca}_{3} \mathrm{Co}_{4} \mathrm{O}_{9}$ by a starch assisted sol-gel combustion method, J. Magn. Magn. Mater. 364, 117 (2014).

${ }^{24}$ Y. Song, Q. Sun, Y. Lu, X. Liu and F. P. Wang, Low-temperature sintering and enhanced thermoelectric properties of $\mathrm{LaCoO}_{3}$ ceramics with $\mathrm{B}_{2} \mathrm{O}_{3}-\mathrm{CuO}$ addition, J. Alloys Compd. 536, 150 (2012).

${ }^{25}$ X. L. Su, F. Fu, Y. G. Yan, G. Zheng, T. Liang, Q. Zhang, X. Cheng, D. W. Yang, H. Chi, X. F. Tang, Q. J. Zhang and C. Uher, Self-propagating high-temperature synthesis for compound 
thermoelectrics and new criterion for combustion processing, Nat. Commun. 5, 4908 (2014).

${ }^{26}$ H. T. Zhu, J. Luo and J. K. Liang, Synthesis of highly crystalline $\mathrm{Bi}_{2} \mathrm{Te}_{3}$ nanotubes and their enhanced thermoelectric properties, J. Mater. Chem. A 2, 12821 (2014).

${ }^{27}$ H. Yang, S. W. Finefrock, J. D. A. Caballero and Y. Wu, Environmentally benign synthesis of ultrathin metal telluride nanowires, J. Am. Chem. Soc. 136, 10242 (2014).

${ }^{28}$ J. P. Fu, S. Y. Song, X. G. Zhang, F. Cao, L. Zhou, X. Y. Li and H. J. Zhang, $\mathrm{Bi}_{2} \mathrm{Te}_{3}$ nanoplates and nanoflowers: Synthesized by hydrothermal process and their enhanced thermoelectric properties, Cryst. Eng. Comm. 14, 2159 (2012).

${ }^{29}$ W. D. Shi, J. B. Yu, H. S. Wang and H. J. Zhang, Hydrothermal synthesis of single-crystalline antimony telluride nanobelts, J. Am. Chem. Soc. 128, 16490 (2006).

${ }^{30}$ S. W. Finefrock, G. Zhang, J.-H. Bahk, H. Fang, H. Yang, A. Shakouri and Y. Wu, Structure and thermoelectric properties of spark plasma sintered ultrathin PbTe nanowires, Nano Lett. 14, 3466 (2014).

${ }^{31}$ H.-T. Zhu, J. Luo and J.-K. Liang, Synthesis of highly crystalline $\mathrm{Bi}_{2} \mathrm{Te}_{3}$ nanotubes and their enhanced thermoelectric properties, $J$. Mater. Chem. A 2, 12821 (2014).

${ }^{32}$ T. J. Zhu, X. Chen, X. Y. Meng, X. B. Zhao and J. He, Anisotropic growth of cubic PbTe nanoparticles to nanosheets: Controlled synthesis and growth mechanisms, Cryst. Growth Des. 10, 3727 (2010).

${ }^{33}$ A. Gharleghi, Y. H. Pai, F. H. Lin and C. J. Liu, Low thermal conductivity and rapid synthesis of $n$-type cobalt skutterudite via a hydrothermal method, J. Mater. Chem. C 2, 4213 (2014).

${ }^{34}$ Z. H. Ge, B. P. Zhang and J. F. Li, Microstructure composite-like $\mathrm{Bi}_{2} \mathrm{~S}_{3}$ polycrystals with enhanced thermoelectric properties, $J$. Mater. Chem. 22, 17589 (2012).

${ }^{35}$ C. Y. Liu, L. Miao, J. H. Zhou, R. Huang and S. Tanemura, Bottom-up assembly to $\mathrm{Ag}$ nanoparticles embedded $\mathrm{Nb}$-doped $\mathrm{TiO}_{2}$ nanobulks with improved $n$-type thermoelectric properties, J. Mater. Chem. 22, 14180 (2012).

${ }^{36}$ K. S. Park, J. S. Son, S. I. Woo, K. S. Shin, M. W. Oh, S. D. Park and T. W. Hyeon, Colloidal synthesis and thermoelectric properties of La-doped $\mathrm{SrTiO}_{3}$ nanoparticles, J. Mater. Chem. A 2, 4217 (2014).

${ }^{37}$ B. Zhou, Y. Zhao, L. Pu and J. J. Zhu, Microwave-assisted synthesis of nanocrystalline $\mathrm{Bi}_{2} \mathrm{Te}_{3}$, Mater. Chem. Phys. 96, 192 (2006).

${ }^{38}$ Q. Yao, Y. J. Zhu, L. D. Chen, Z. L. Sun and X. H. Chen, Microwave-assisted synthesis and characterization of $\mathrm{Bi}_{2} \mathrm{Te}_{3}$ nanosheets and nanotubes, J. Alloys Compd. 481, 91 (2009).

${ }^{39}$ G. H. Dong, Y. J. Zhu and L. D. Chen, Microwave-assisted rapid synthesis of $\mathrm{Sb}_{2} \mathrm{Te}_{3}$ nanosheets and thermoelectric properties of bulk samples prepared by spark plasma sintering, J. Mater. Chem. 20, 1976 (2010).

${ }^{40}$ H. M. Xu, G. Chen, R. C. Jin, D. H. Chen, Y. Wang, J. Pei, Y. Q. Zhang, C. S. Yan and Z. Z. Qiu, Microwave-assisted synthesis of $\mathrm{Bi}_{2} \mathrm{Se}_{3}$ ultrathin nanosheets and its electrical conductivities, Cryst. Eng. Comm. 16, 3965 (2014).

${ }^{41}$ Q. H. Jiang, H. X. Yan, J. Khaliq, Y. Shen, K. Simpson and M. J. Reece, Enhancement of thermoelectric properties by atomicscale percolation in digenite $\mathrm{Cu}_{x} \mathrm{~S}$, J. Mater. Chem. A 2, 9486 (2014).
${ }^{42}$ Q. H. Jiang, H. X. Yan, J. Khaliq, H. P. Ning, S. Grasso, K. Simpson and M. J. Reece, Large ZT enhancement in hot forged nanostructured $p$-type $\mathrm{Bi}_{0.5} \mathrm{Sb}_{1.5} \mathrm{Te}_{3}$ bulk alloys, J. Mater. Chem. A 2, 5785 (2014).

${ }^{43}$ S. Bathula, B. Gahtori, M. Jayasimhadri, S. K. Tripathy, K. Tyagi, A. K. Srivastava and A. Dhar, Microstructure and mechanical properties of thermoelectric nanostructured $n$-type silicon-germanium alloys synthesized employing spark plasma sintering, Appl. Phys. Lett. 105, 061902 (2014).

${ }^{44}$ B. Poudel, Q. Hao, Y. Ma, Y. C. Lan, A. Minnich, B. Yu, X. Yan, D. Z. Wang, A. Muto, D. Vashaee, X. Y. Chen, J. M. Liu, M. S. Dresselhaus, G. Chen and Z. F. Ren, High-thermoelectric performance of nanostructured bismuth antimony telluride bulk alloys, Sci. 320, 634 (2008).

${ }^{45}$ Y. Zheng, Q. Zhang, X. L. Su, H. Y. Xie, S. C. Shu, T. L. Chen, G. J. Tan, Y. G. Yan, X. F. Tang, C. Uher and G. J. Snyder, Mechanically robust BiSbTe alloys with superior thermoelectric performance: A case study of stable hierarchical nanostructured thermoelectric materials, Adv. Energy Mater. 5, 1401391 (2015).

${ }^{46}$ T. T. Luo, S. Y. Wang, H. Li and X. F. Tang, Low temperature thermoelectric properties of melt spun $\mathrm{Bi}_{85} \mathrm{Sb}_{15}$ alloys, Intermetallics 32, 96 (2013).

${ }^{47}$ X. L. Su, H. Li, Y. G. Yan, G. Y. Wang, H. Chi, X. Y. Zhou, X. F. Tang, Q. J. Zhang and C. Uher, Microstructure and thermoelectric properties of $\mathrm{CoSb}_{2.75} \mathrm{Ge}_{0.25-x}$ Tex prepared by rapid solidification, Acta Mater. 60, 3536 (2012).

${ }^{48}$ M. Hasaka, T. Morimura and H. Nakashima, Thermoelectric properties of Melt-Spun $\mathrm{Zn}_{x} \mathrm{Sb}_{3}$ ribbons, J. Electron. Mater. 41, 1193 (2012).

${ }^{49}$ B. L. Du, H. Li, J. J. Xu, X. F. Tang and C. Uher, Enhanced thermoelectric performance and novel nanopores in $\mathrm{AgSbTe}_{2}$ prepared by melt spinning, J. Solid State Chem. 184, 109 (2011).

${ }^{50}$ P. Zhang, Z. Wang, H. Chen, H. J. Yu, L. Zhu and X. Y. Jian, Effect of cooling rate on microstructural homogeneity and grain size of $n$-Type Si-Ge thermoelectric alloy by melt spinning, $J$. Electron. Mater. 39, 2251 (2010).

${ }^{51}$ M. Kumagai, K. Kurosaki, N. Uchida, Y. Ohishi, H. Muta and S. Yamanaka, Synthesis and characterization of melt-spun metastable $\mathrm{Al}_{6} \mathrm{Ge}_{5}$, J. Electron. Mater. 44, 948 (2015).

${ }^{52}$ G. J. Tan, W. Liu, S. Y. Wang, Y. G. Yan, H. Li, X. F. Tang and C. Uher, Rapid preparation of $\mathrm{CeFe}_{4} \mathrm{Sb}_{12}$ skutterudite by melt spinning: rich nanostructures and high thermoelectric performance, J. Mater. Chem. A 1, 12657 (2013).

${ }^{53}$ Y. H. Lin, J. L. Lan, Z. J. Shen, Y. H. Liu, C. W. Nan and J. F. Li, High-temperature electrical transport behaviors in textured $\mathrm{Ca}_{3} \mathrm{Co}_{4} \mathrm{O}_{9}$-based polycrystalline ceramics, Appl. Phys. Lett. 94, 072107 (2009).

${ }^{54}$ C. Chen, D. W. Liu, B. P. Zhang and J. F. Li, Enhanced thermoelectric properties obtained by compositional optimization in p-type $\mathrm{Bi}_{x} \mathrm{Sb}_{2-x} \mathrm{Te}_{3}$ fabricated by mechanical alloying and spark plasma sintering, J. Electron. Mater. 40, 942 (2011).

${ }^{55}$ C. Chen, B. P. Zhang, D. W. Liu and Z. H. Ge, Thermoelectric properties of $\mathrm{Cu}_{y} \mathrm{Bi}_{x} \mathrm{Sb}_{2-x-y} \mathrm{Te}_{3}$ alloys fabricated by mechanical alloying and spark plasma sintering, Intermetallics 25, 131 (2012).

${ }^{56}$ E. J. Gonzalez, J. E. Blendell, J. P. Cline, J. J. Ritter, P. Maruthamuthu, E. H. Nelson and S. B. Horn, Texture development in $\mathrm{Bi}_{2} \mathrm{Te}_{3}$ during hot forging, J. Mater. Res. 13, 766 (1998).

${ }^{57}$ J. L. Lan, Y. C. Liu, B. Zhan, Y. H. Lin, B. P. Zhang, X. Yuan, W. Q. Zhang, W. Xu and C. W. Nan, Enhanced thermoelectric 
properties of $\mathrm{Pb}$-doped $\mathrm{BiCuSeO}$ ceramics, Adv. Mater. 25, 5086 (2013).

${ }^{58}$ Y. Liu, J. L. Lan, W. Xu, Y. C. Liu, Y. L. Pei, B. Cheng, D. B. Liu, Y. H. Lin and L. D. Zhao, Enhanced thermoelectric performance of a $\mathrm{BiCuSeO}$ system via band gap tuning, Chem. Commun. 49, 8075 (2013).

${ }^{59}$ W. Xu, Y. Liu, L. D. Zhao, P. F. An, Y. H. Lin, A. Marcelli and Z. Y. Wu, Evidence of an interlayer charge transfer route in $\mathrm{BiCu}_{1-x} \mathrm{SeO}$, J. Mater. Chem. A 1, 12154 (2013).

${ }^{60}$ Y. L. Pei, J. Q. He, J. F. Li, F. Li, Q. J. Liu, W. Pan, C. Barreteau, D. Berardan, N. Dragoe and L. D. Zhao, High thermoelectric performance of oxyselenides: Intrinsically low thermal conductivity of Ca-doped BiCuSeO, NPG Asia Mater. 5, e47 (2013).

${ }^{61}$ Y. Liu, L. D. Zhao, Y. C. Liu, J. L. Lan, W. Xu, F. Li, B. P. Zhang, D. Berardan, N. Dragoe, Y. H. Lin, C. W. Nan, J. F. Li and H. M. Zhu, Remarkable enhancement in thermoelectric performance of $\mathrm{BiCu}-$ SeO by Cu deficiencies, J. Am. Chem. Soc. 133, 20112 (2011).

${ }^{62}$ X. Z. Chen, F. Li, Y. Dong, B. B. Liang, L. J. Wang, L. D. Chen and W. Jiang, Fabrication of micro/nano-structured $\mathrm{Bi}_{2} \mathrm{Te}_{3}$ bulk materials with low thermal conductivity by spark plasma sintering, J. Am. Ceram. Soc. 95, 2096 (2012).

${ }^{63}$ P. Y. Lee, T. C. Chen, J. Y. Huang, H. L. Hsieh and J. S. C. Jang, Enhancement of the thermoelectric performance in nano-/micro-structured $p$-type $\mathrm{Bi}_{0.4} \mathrm{Sb}_{1.6} \mathrm{Te}_{3}$ fabricated by mechanical alloying and vacuum hot pressing, J. Alloys Compd. 615, S476 (2014).

${ }^{64}$ W. Zhu, J. Y. Yang, D. X. Zhou, C. J. Xiao and X. K. Duan, Electrochemical aspects and structure characterization of VA-VIA compound semiconductor $\mathrm{Bi}_{2} \mathrm{Te}_{3} / \mathrm{Sb}_{2} \mathrm{Te}_{3}$ superlattice thin films via electrochemical atomic layer epitaxy, Langmuir 24, 5919 (2008).

${ }^{65}$ Y. Q. Cao, X. B. Zhao, T. J. Zhu, X. B. Zhang and J. P. Tu, Syntheses and thermoelectric properties of $\mathrm{Bi}_{2} \mathrm{Te}_{3} / \mathrm{Sb}_{2} \mathrm{Te}_{3}$ bulk nanocomposites with laminated nanostructure, Appl. Phys. Lett. 92, 143106 (2008).

${ }^{66}$ M. H. Lee, J. S. Rhyee, M. Vaseem, Y. B. Hahn, S. D. Park, H. J. Kim, S. J. Kim, H. J. Lee and C. Kim, Thermoelectric properties of $\mathrm{SrTiO}_{3}$ nano-particles dispersed indium selenide bulk composites, Appl. Phys. Lett. 102, 223901 (2013).

${ }^{67}$ S. J. Poon, A. S. Petersen and D. Wu, Thermal conductivity of core-shell nanocomposites for enhancing thermoelectric performance, Appl. Phys. Lett. 102, 173110 (2013).

${ }^{68}$ N. Zhou, G. Chen, X. S. Zhang, Y. C. Xu, B. R. Xu and M. Q. Li, Size-controlled synthesis and transport properties of $\mathrm{Sb}_{2} \mathrm{Te}_{3}$ nanoplates, RSC Adv. 4, 2427 (2014).

${ }^{69}$ Y. Liu, C. L. Ou, J. G. Hou and H. M. Zhu, Effect of coated $\mathrm{TiO}_{2}$ nano-particle on thermoelectric performance of $\mathrm{TiC}_{0.5} \mathrm{O}_{0.5}$ ceramics, J. Alloys Compd. 531, 5 (2012).

${ }^{70}$ R. C. Jin, G. Chen, J. Pei and C. S. Yan, Hydrothermal synthesis and thermoelectric transport property of $\mathrm{PbS}-\mathrm{PbTe}$ core-shell heterostructures, New J. Chem. 36, 2574 (2012).

${ }^{71}$ L. W. Fu, J. Y. Yang, J. Y. Peng, Q. H. Jiang, Y. Xiao, Y. B. Luo, D. Zhang, Z. W. Zhou, M. Y. Zhang, Y. D. Cheng and F. Q. Cheng, Enhancement of thermoelectric properties of Yb-filled skutterudites by an Ni-Induced core-shell structure, J. Mater. Chem. A 3, 1010 (2015).

${ }^{72}$ B. Feng, J. Xie, G. S. Cao, T. J. Zhu and X. B. Zhao, Enhanced thermoelectric properties of $p$-type $\mathrm{CoSb}_{3} /$ graphene nanocomposite, J. Mater. Chem. A 1, 13111 (2013).
${ }^{73}$ N. Satyala, A. Tahmasbi Rad, Z. Zamanipour, P. Norouzzadeh, J. S. Krasinski, L. Tayebi and D. Vashaee, Reduction of thermal conductivity of bulk nanostructured bismuth telluride composites embedded with silicon nano-inclusions, J. Appl. Phys. 115, 044304 (2014).

${ }^{74}$ J. H. Li, Q. Tan, J. F. Li, D. W. Liu, F. Li, Z. Y. Li, M. M. Zou and K. Wang, BiSbTe-based nanocomposites with high ZT: The effect of SiC nanodispersion on thermoelectric properties, Adv. Funct. Mater. 23, 4317 (2013).

${ }^{75}$ Y. Xiao, J. Y. Yang, Q. H. Jiang, L. W. Fu, Y. B. Luo, M. Liu, D. Zhang, M. Y. Zhang, W. X. Li, J. Y. Peng and F. Q. Chen, A simultaneous increase in the ZT and the corresponding critical temperature of $p$-type $\mathrm{Bi}_{0.4} \mathrm{Sb}_{1.6} \mathrm{Te}_{3}$ by a combined strategy of dual nanoinclusions and carrier engineering, J. Mater. Chem. A 2, 20288 (2014).

${ }^{76}$ N. Wang, L. Han, H. C. He, Y. H. Ba and K. Koumoto, Effects of mesoporous silica addition on thermoelectric properties of Nb-doped $\mathrm{SrTiO}_{3}$, J. Alloys Compd. 497, 308 (2010).

${ }^{77}$ N. Wang, H. J. Chen, H. C. He, W. Norimatsu, M. Kusunoki and K. Koumoto, Enhanced thermoelectric performance of Nb-doped $\mathrm{SrTiO}_{3}$ by nano-inclusion with low thermal conductivity, Sci. Rep. 3, 03449 (2013).

${ }^{78}$ J. Y. Peng, L. W. Fu, Q. Z. Liu, M. Liu, J. Y. Yang, D. Hitchcock, M. H. Zhou and J. He, A study of $\mathrm{Yb}_{0.2} \mathrm{Co}_{4} \mathrm{Sb}_{12}-\mathrm{AgSbTe}_{2}$ nanocomposites: Simultaneous enhancement of all three thermoelectric properties, J. Mater. Chem. A 2, 73 (2014).

${ }^{79}$ F. Yang, X. A. Fan, Z. Z. Rong, X. Z. Cai and G. Q. Li, Lattice thermal conductivity reduction due to in situ-generated nanophase in $\mathrm{Bi}_{0.4} \mathrm{Sb}_{1.6} \mathrm{Te}_{3}$ alloys by microwave-activated hot pressing, J. Electron. Mater. 43, 4327 (2014).

${ }^{80}$ S. I. Cha, K. T. Kim, S. N. Arshad, C. B. Mo and S. H. Hong, Extraordinary strengthening effect of carbon nanotubes in metalmatrix nanocomposites processed by molecular-level mixing, $A d v$. Mater. 17, 1377 (2005).

${ }^{81}$ Z. J. Shen, Z. Zhao, H. Peng and M. Nygren, Formation of tough interlocking microstructures in silicon nitride ceramics by dynamic ripening, Nature 417, 266 (2002).

${ }^{82}$ H. X. Yan, H. T. Zhang, R. Ubic, M. J. Reece, J. Liu, Z. J. Shen and $\mathrm{Z}$. Zhang, A lead-free high-Curie-point ferroelectric ceramic, $\mathrm{CaBi}_{2} \mathrm{Nb}_{2} \mathrm{O}_{9}$, Adv. Mate. 17, 1261 (2005).

${ }^{83}$ C. Chen, Q. H. Jiang, X. Wei, I. Abrahams, H. X. Yan and M. J. Reece, Three layer perovskite-like structured $\mathrm{Pr}_{3} \mathrm{Ti}_{2} \mathrm{TaO}_{11}$ ferroelectrics with super-high curie point, J. Am. Ceram. Soc. 97, 3624 (2014)

${ }^{84}$ G. Delaizir, G. Bernard-Granger, J. Monnier, R. Grodzki, O. KimHak, P. D. Szkutnik, M. Soulier, S. Saunier, D. Goeuriot, O. Rouleau, J. Simon, C. Godart and C. Navone, A comparative study of spark plasma sintering (SPS), hot isostatic pressing (HIP) and microwaves sintering techniques on $p$-type $\mathrm{Bi}_{2} \mathrm{Te}_{3}$ thermoelectric properties, Mater. Res. Bull. 47, 1954 (2012).

${ }^{85}$ N. Chawake, L. D. Pinto, A. K. Srivastav, K. Akkiraju, B. S. Murty and R. S. Kottada, On Joule heating during spark plasma sintering of metal powders, Scr. Mater. 93, 52 (2014).

${ }^{86} \mathrm{~S}$. Munoz and U. Anselmi-Tamburini, Parametric investigation of temperature distribution in field activated sintering apparatus, Int. J. Adv. Manuf. Technol. 65, 127 (2013).

${ }^{87}$ K. Vanmeensel, A. Laptev, J. Hennicke, J. Vleugels and O. Van der Biest, Modelling of the temperature distribution during field assisted sintering, Acta Mater. 53, 4379 (2005). 
${ }^{88}$ S. Muñoz and U. Anselmi-Tamburini, Temperature and stress fields evolution during spark plasma sintering processes, J. Mater. Sci. 45, 6528 (2010).

${ }^{89} \mathrm{~S}$. Grasso and Y. Sakka, Electric field in SPS: Geometry and pulsed current effects, J. Ceram. Soc. Jpn. 121, 524 (2013).

${ }^{90}$ L. D. Zhao, S. H. Lo, Y. S. Zhang, H. Sun, G. J. Tan, C. Uher, C. Wolverton, V. P. Dravid and M. G. Kanatzidis, Ultralow thermal conductivity and high thermoelectric figure of merit in $\mathrm{SnSe}$ crystals, Nature 5208, 373 (2014).

${ }^{91}$ Y. B. Luo, J. Y. Yang, Q. H. Jiang, L. W. Fu, Y. Xiao, W. X. Li, D. Zhang, Z. W. Zhou and Y. D. Cheng, Melting and solidification of bismuth antimony telluride under a high magnetic field: A new route to high thermoelectric performance, Nano Energy 15, 709 (2015).
${ }^{92} \mathrm{H}$. Wu, B. Hu, N. J. Tian and Q. G. Zheng, Preparation of beta$\mathrm{FeSi}_{2}$ thermoelectric material by laser sintering, Mater. Lett. $\mathbf{6 5}$, 2877 (2011).

${ }^{93}$ B. Stoib, T. Langmann, N. Petermann, S. Matich, M. Sachsenhauser, H. Wiggers, M. Stutzmann and M. S. Brandt, Morphology, thermoelectric properties and wet-chemical doping of laser-sintered germanium nanoparticles, Phys. Status Solidi A, Appl. Mater. Sci. 210, 153 (2013).

${ }^{94}$ G. Liu, G. J. Zhang, F. Jiang, X. D. Ding, Y. J. Sun, J. Sun and E. Ma, Nanostructured high-strength molybdenum alloys with unprecedented tensile ductility, Nature Mater. 12, 344 (2013).

${ }^{95}$ L. Jiang, J. K. Li, P. M. Cheng, G. Liu, R. H. Wang, B. A. Chen, J. Y. Zhang, J. Sun, M. X. Yang and G. Yang, Microalloying ultrafine grained Al alloys with enhanced ductility, Sci. Rep. 4, 3605 (2014). 